\title{
A Wind-powered Rover for a Low-Cost Venus Mission
}

\author{
Gina Benigno ${ }^{1}$ \\ Towson University, Towson, MD 21252 \\ Kathleen $\mathrm{Hoza}^{1}$ \\ Massachusetts Institute of Technology, Cambridge, MA 02139 \\ Samira Motiwala ${ }^{1,2}$ \\ Stanford University, Stanford, CA 94305 \\ Geoffrey A. Landis, ${ }^{3}$ \\ NASA John H. Glenn Research Center, Cleveland, OH 44135 \\ Anthony J. Colozza ${ }^{4}$ \\ Vantage Partners LLC, Cleveland, $\mathrm{OH} 44135$
}

\begin{abstract}
Venus, with a surface temperature of $450^{\circ} \mathrm{C}$ and an atmospheric pressure 90 times higher than that of the Earth, is a difficult target for exploration. However, high-temperature electronics and power systems now being developed make it possible that future missions may be able to operate in the Venus environment. Powering such a rover within the scope of a Discovery class mission will be difficult, but harnessing Venus' surface winds provides a possible way to keep a powered rover small and light. This project scopes out the feasibility of a wind-powered rover for Venus surface missions. Two rover concepts, a landsailing rover and a wind-turbine-powered rover, were considered. The turbine-powered rover design is selected as being a low-risk and low-cost strategy. Turbine detailed analysis and design shows that the turbine can meet mission requirements across the desired range of wind speeds by utilizing three constant voltage generators at fixed gear ratios.
\end{abstract}

\section{Nomenclature}

$\begin{array}{ll}A_{\text {rotor }} & =\text { Rotor area } \\ A_{\text {blades }} & =\text { Blade area } \\ A_{\text {sail }} & =\text { Blade area } \\ \mathrm{AR} & =\text { Aspect ratio } \\ b & =\text { Sail luff height } \\ C_{D} & =\text { Drag coefficient } \\ C_{L} & =\text { Lift coefficient } \\ C_{r} & =\text { Rolling resistance } \\ \mathrm{CP} & =\text { Center of pressure } \\ F_{p} & =\text { Propulsive force } \\ F_{S} & =\text { Sail force } \\ g & =\text { Gravitational acceleration } \\ h & =\text { Height }\end{array}$

${ }^{1}$ NASA Space Academy 2012, NASA Glenn Research Center, Cleveland OH

2 AIAA Student member

${ }^{3}$ NASA John Glenn Research Center, mailstop 302-1, 21000 Brookpark Road, Cleveland OH 44135. AIAA Associate Fellow

${ }^{4}$ Vantage Partners, LLC, John Glenn Research Center, mailstop 309-1, 21000 Brookpark Road, Cleveland OH 44135 . 
paper AIAA-2013-0586, 51st AIAA Aerospace Sciences Meeting, Grapevine TX, Jan. 7-10 2013

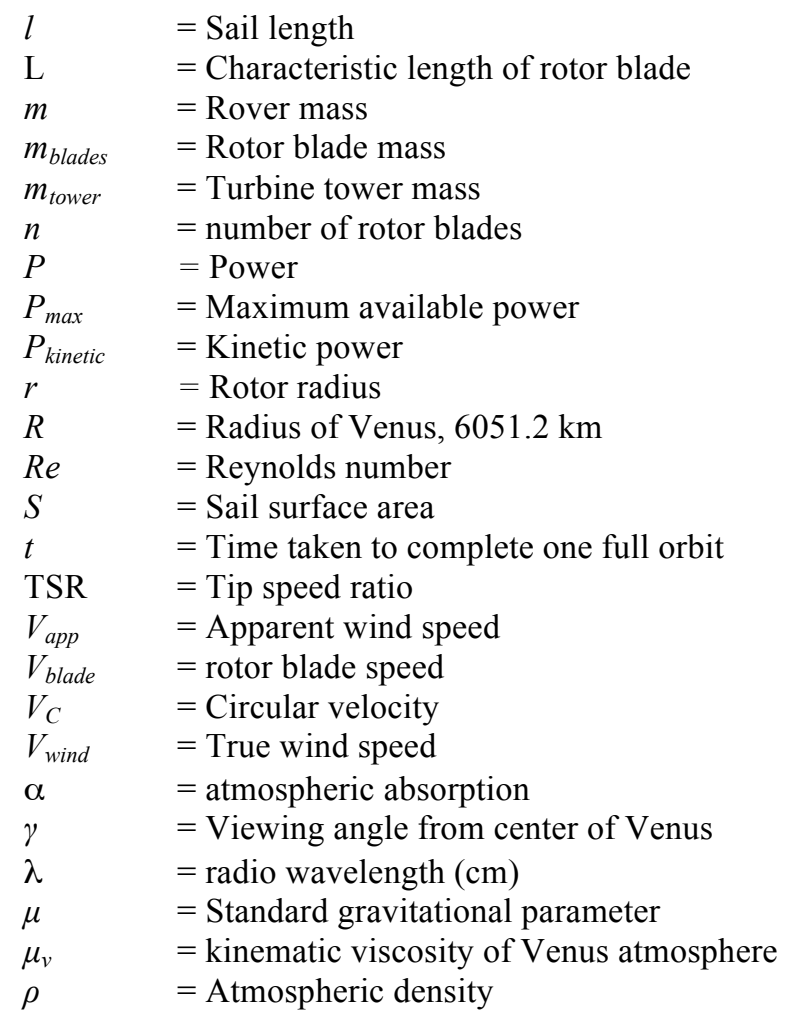

\section{Introduction}

Venus is one of the more scientifically interesting planets in our solar system, yet is relatively unexplored, and much is still unknown about the planet. While similar in size, density, and surface gravity, Venus is also quite different from our own planet, Earth. It has a surface temperature of $464^{\circ} \mathrm{C}$, and an atmosphere mainly composed of Carbon Dioxide (96.5\%) and Nitrogen (3.5\%) at surface pressure of 92 Bar. $^{1}$

These surface conditions make design of a spacecraft to penetrate the Venusian atmosphere difficult. Previous missions to the Venusian surface have been quickly destroyed by the extreme surface temperature and pressure. The longest-lasting spacecraft on the Venusian surface to date is the Russian Venera 13 lander, which managed to survive Venus's surface conditions for 127 minutes before losing its connection with Earth.

Most electronics designed for use on Earth are not able to withstand surface temperatures upwards of $400^{\circ} \mathrm{C}$; however, several institutions are successfully developing high-temperature electronic components, using silicon carbide and other wide-bandgap semiconductor based electronics. ${ }^{2}$ Currently, they have successfully tested silicon carbide based electronics at $500^{\circ} \mathrm{C}^{3}$ for extended periods of time. The further developments of these silicon-carbide based electronics will be invaluable for future missions to Venus. ${ }^{4}$ They will contribute to not only the scientific instruments, but also communications systems, as well as potential mechanical systems for a Venus rover. ${ }^{5}$

Venus's opaque atmosphere makes it difficult to study the surface from space, except by radar images. Magellan was able to successfully map out $98 \%$ of Venus's surface, ${ }^{6}$ however, only so much can be discovered about a planet by images taken from orbit; detailed exploration requires "ground truth" to be established from surface missions.

Whereas short-lived probes have successfully landed on the surface of Venus, a rover has yet to be sent there. Recent Mars missions have shown the value of rovers on planetary surfaces, allowing the ability to do observations at multiple locations, rather than being stuck to just the landing location. A rover may also have the ability to scrape under the surface of Venus; it is likely that the rocks and soil are chemically altered through interaction with the atmosphere of Venus. Being able to study underneath the soil and the insides of rocks could provide us with entirely new information by accessing samples unaltered by contact with the Venusian atmosphere.

With the use of high-temperature electronics, the goal of this rover mission is to be able to survive for many days. A longer lifetime means a much longer record of atmospheric and surface conditions can be taken, covering a large part, if not all, of a Venus solar day.

Fig. 1 illustrates an artist's conception of this conceptual design for the Venus rover. 


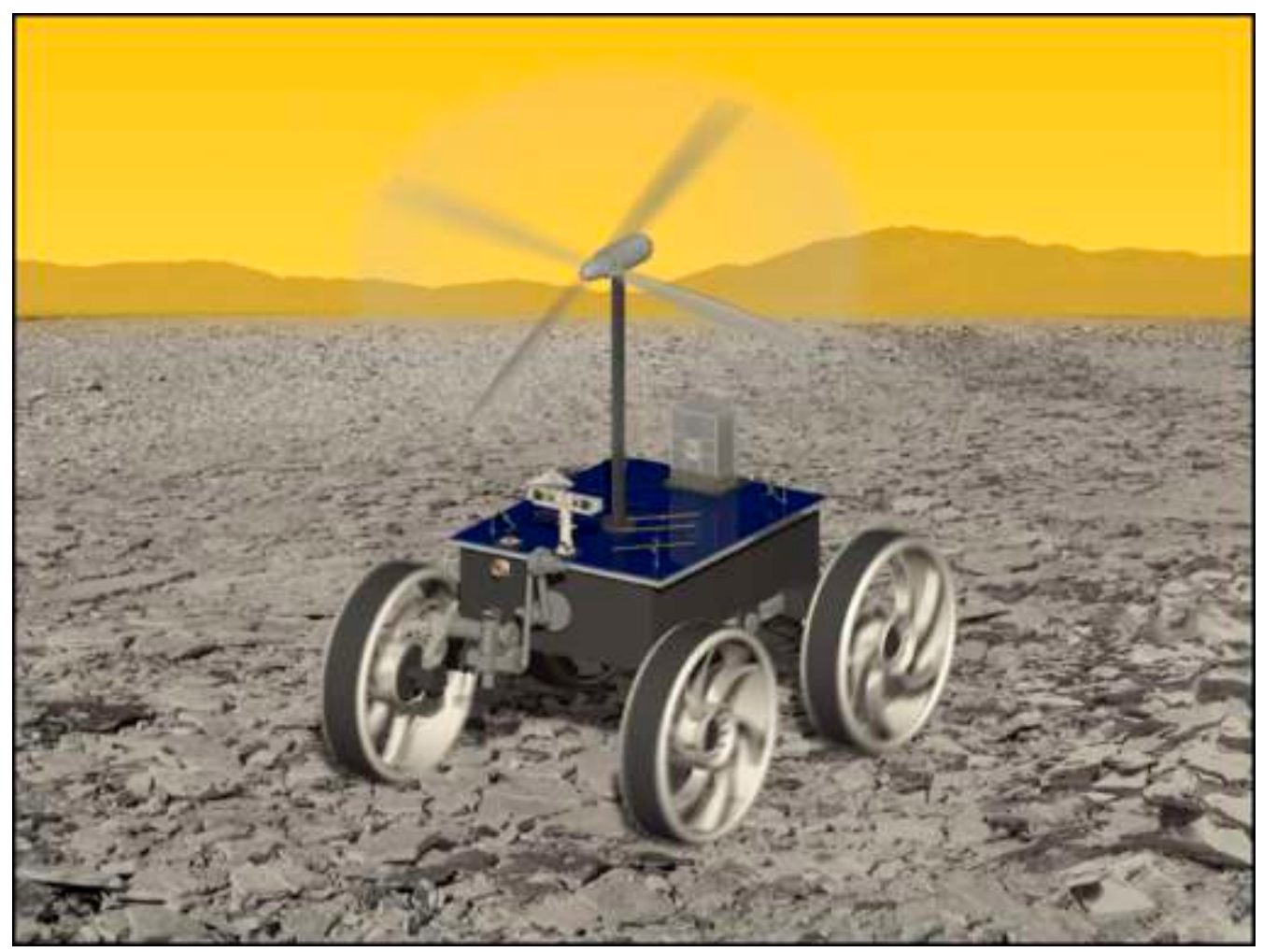

Figure 1. Artist's Conception of Venus Rover

\section{Venus Rover Concept}

High surface temperature conditions on Venus poses a significant challenge to designing a Venus power systems. Previously proposed rover designs 7,8 implemented the use of radioisotope power systems, which produce power by converting the heat from radioactive decay into electricity, using either thermoelectric conversion ("Radioisotope Thermoelectric Generators," or "RTG")9 or Stirling10 conversion technology. Although they have been proposed for use on Venus,11 radioisotope power systems are expensive and heavy,12 and also may have difficulties operating in the corrosive, high-temperature, high-pressure environment of Venus, which may makes them unsuitable for a Venus mission. The cost and lack of availability of the plutonium isotope make them a poor choice for a low-cost, Discovery class mission.

In this design study, we analyze an alternative method for generating power: harnessing the wind on Venus as a power source for a rover. Wind speeds on the surface of Venus have been directly measured only at four sites on the Venus surface, at which the Venera probes found13,14 speeds in a range of 0.3 to $0.9 \mathrm{~m} / \mathrm{s}$. Although the absolute speed is slow compared to winds on Earth, the density of the Venus atmosphere is high enough that this wind can be used to generate force.

This study analyzed two main rover concepts: a "landsail" rover and a wind turbine-powered rover. These concepts rely on surface winds to generate power for the scientific instruments and for mobility. Design assumptions for these concepts include wind speeds of $0.3 \mathrm{~m} / \mathrm{s}$ (worst-case scenario) and $0.6 \mathrm{~m} / \mathrm{s}$ (most likely or average case scenario), a rover base mass of $70 \mathrm{~kg}$, rolling resistance of 0.05 (the equivalent of a stagecoach on a dirt road), power requirements of $30 \mathrm{Watts}$ for scientific instruments, and total energy of $233 \mathrm{~W}$-h per science stop.

\section{A. Landsailer Design}

The Venus landsailer concept is in essence a sailboat on wheels, as depicted in Fig. 2.15 The sail can be treated as an airfoil, which develops aerodynamic forces as air flows past the sail. These forces may be decomposed into components of lift and drag, perpendicular and parallel to the airflow, respectively.

The apparent wind speed is the speed relative to the moving vehicle, and is the vector sum of the true wind speed (wind speed relative to the ground) and the speed of the vehicle relative to the ground. ${ }^{16}$ However, for the Venus landsailer, the velocity of the vehicle will be low compared to the wind speed, and hence the apparent wind speed can be assumed to be equal to the true wind speed, $V_{\text {wind }}$. 


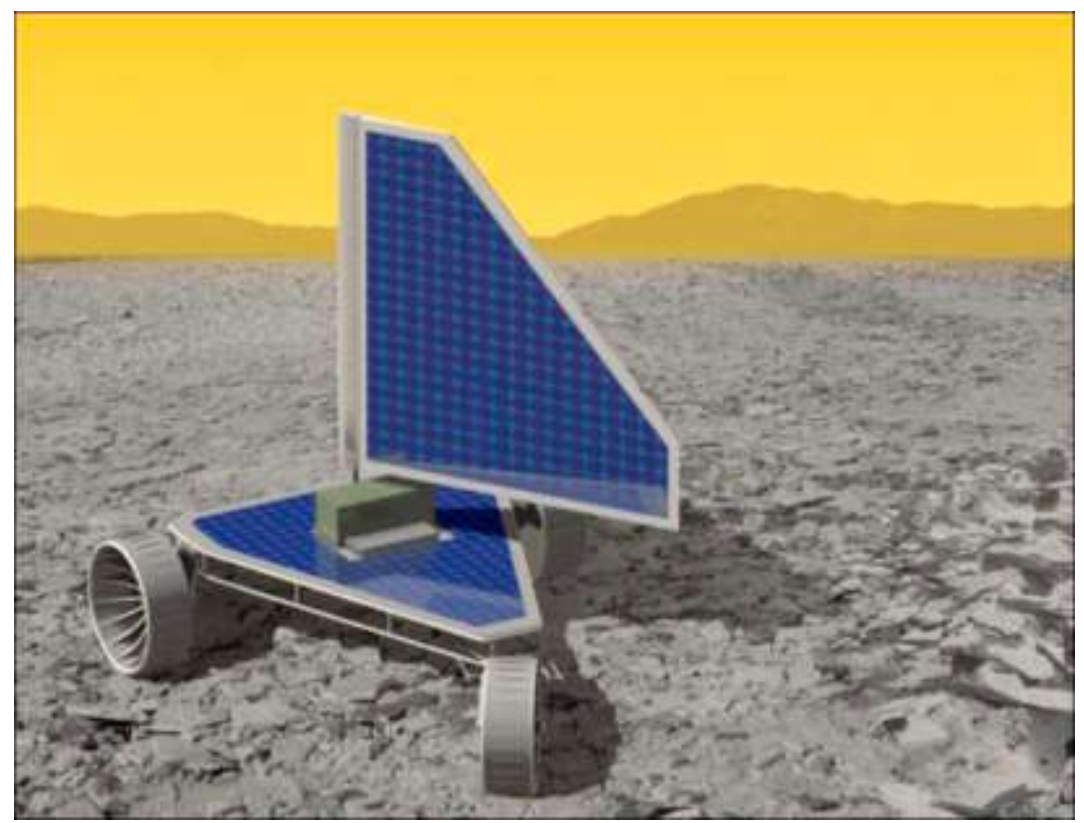

Figure 2. Venus Landsail Concept (from ref. 15)

Thus, the force on the sail can be calculated by the lift equation:

$$
F=\frac{1}{2} \rho V_{\text {wind }}^{2} A_{\text {sail }} C_{L}
$$

where $\rho$ is the air density on Venus $\left(67 \mathrm{~kg} / \mathrm{m}^{3}\right), V_{\text {wind }}$ is the wind speed, $A_{\text {sail }}$ is the sail surface area, and $C_{L}$ is the aerodynamic coefficient. Although the atmospheric density is high compared to that of Earth, the wind speeds are much lower, resulting in a similar Reynolds number for the Venus rover in comparison to typical terrestrial sails.

The force required to propel a vehicle depends on the rolling resistance, which is a function of both the terrain and the wheel type and size:

$$
F=C_{r} m g
$$

where $C_{r}$ is the coefficient of rolling friction, $m$ is the rover body mass, and $g$ is the gravitational acceleration on Venus $\left(8.87 \mathrm{~m} / \mathrm{s}^{2}\right)$. The minimum size of the sail needed to move the rover for assumed parameters can be computed by setting the two forces equal to each other. Fig. 4 shows a graph of the minimum sail area as a function of mass for rolling resistance coefficients ranging between 0.02 (rolled new gravel) and 0.08 (medium hard soil), since the rolling resistance of the rover on Venus is just an assumed parameter for an unknown environment and wheel design.

The star on Fig. 3 indicates the sail area size for the assumed parameters of $70 \mathrm{~kg}$ rover mass and 0.05 rolling resistance, which yields a minimum sail area of $10.64 \mathrm{~m}^{2}$ needed to move the vehicle.

The sail itself can be dimensionalized by considering different aspect ratios (AR) of the sail. The aspect ratio is defined as:

$$
A R=\frac{b^{2}}{A_{\text {sail }}}
$$

where $b$ is the length of the luff and $A_{\text {sail }}$ is the surface area of the sail. The sail may be estimated as a simple geometric triangle with height $b$ and length $l$, as shown in Fig. 4.

CP represents the center of pressure, which is estimated as $1 / 3$ the height from the base of the triangle. Aspect ratios determine the efficiency of the sail, because higher aspect ratios yield lower lift-induced drag. Typical aspect ratios for terrestrial sails range between 1 and 6; higher aspect ratios generate more lift but experience stall at high angles of attack whereas lower aspect ratios generate greater drag. ${ }^{16}$ A polar diagram by Marchaj ${ }^{17}$ showing lift versus drag with plotted data for sails for different aspect ratios show that the most favorable aspect ratios for ocean cruising and maximum performance are between 2.5 and 3.5.

Table 2 shows different aspect ratios and their corresponding lengths and the center of pressure location for the sail area size determined. Packaging and center of pressure create challenges to sail design, so the lower aspect ratio of 2 was chosen to keep the height of the mast lower. This results in a triangular sail with a $45^{\circ}$ base angle. 
paper AIAA-2013-0586, 51st AIAA Aerospace Sciences Meeting, Grapevine TX, Jan. 7-10 2013

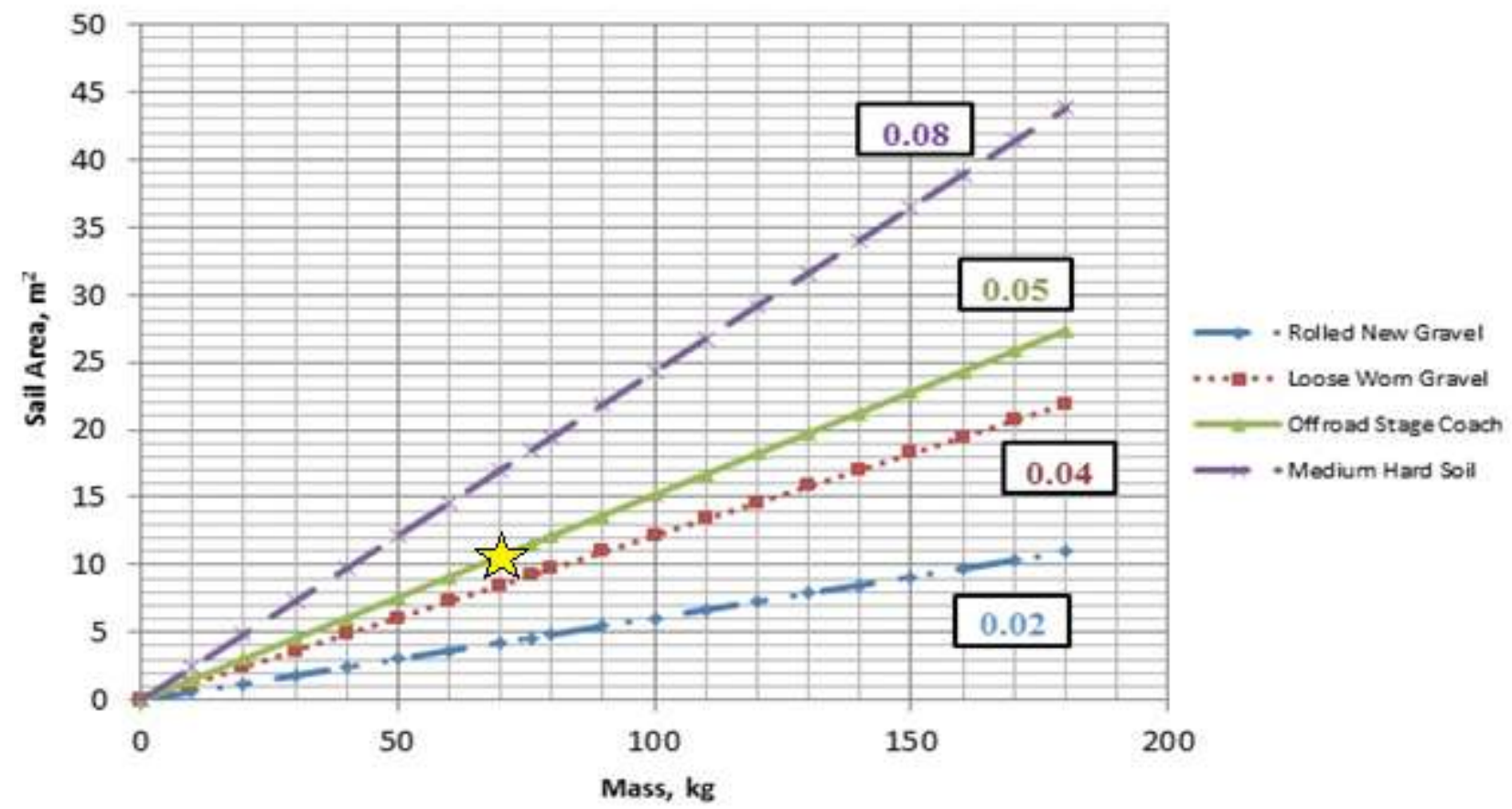

Figure 3. Sail Area vs. Mass for Various Rolling Resistances

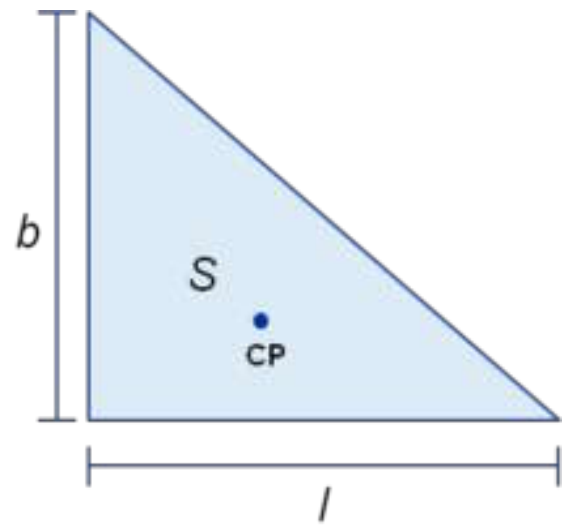

Figure 4. Sail Geometric Shape

Table 2. Sail Dimensions for Various Aspect Ratios

\begin{tabular}{|c|c|c|c|}
\hline \multicolumn{5}{|c|}{$\mathbf{A}_{\text {sail }}=\mathbf{1 0 . 6 4} \mathbf{~ m}^{\mathbf{2}}$} \\
\hline $\mathbf{A R}$ & $\boldsymbol{b}(\mathbf{m})$ & $\boldsymbol{l}(\mathbf{m})$ & $\mathbf{C P}(\mathbf{m})$ \\
\hline 1 & 3.26 & 6.52 & 1.09 \\
\hline 2 & 4.61 & 4.61 & 1.54 \\
\hline 3 & 5.65 & 3.77 & 1.88 \\
\hline 4 & 6.52 & 3.26 & 2.17 \\
\hline 5 & 7.29 & 2.92 & 2.43 \\
\hline 6 & 7.99 & 2.66 & 2.66 \\
\hline
\end{tabular}

5

American Institute of Aeronautics and Astronautics 
Given the center of pressure, the base of the rover needs to be sized so that the force generated on the sail (approximately 31 Newtons) does not cause the rover to tip and be unable to recover. A base width of 0.35 meters is required to overcome this force; the width is designed for 0.5 meters to include margin.

Power can generated from two main sources for this conceptual design: work done on the sail from the aerodynamic force (e.g., acting on a generator attached to the wheels) or from solar cells placed on the sail surface or on the rover body. The power requirements for the mission are 30 Watts for science instruments and an additional 30 Watts for steering and mechanisms (which need not be operated simultaneously). Wind imparting kinetic energy onto the sail cannot transfer all of its energy to the sail. The Betz limit dictates the maximum power available for a wind turbine: ${ }^{16}$

$$
P_{\text {max }}=\frac{16}{27} P_{\text {kinetic }}=\frac{16}{27}\left(\frac{1}{2} \rho V_{\text {wind }}^{3} A\right)
$$

However, sails are typically only one-fourth as effective as wind turbines in extracting the wind's energy, and the maximum power achieved occurs when the rover speed is $1 / 3$ of the true wind speed, where the wind does more work on the relatively slow-moving vehicle because it is required to "push" harder. ${ }^{16}$. For this case

where $C_{D}$ is the drag coefficient on the sail.

$$
P_{\text {max }}=\frac{2}{27}\left(\frac{1}{2} \rho V_{\text {wind }}^{3} A_{\text {sail }} C_{D}\right)
$$

Solar cells operate poorly at the Venus surface due to both the low light levels and the high temperature. However, photovoltaic solar cells have been calculated to have some performance on the surface of Venus. Dualjunction PV solar cells have about $0.2 \%$ efficiency at the surface and require an estimated $1.6 \mathrm{~m}^{2}$ of surface area to generate 1 Watt of power. ${ }^{18}$ Table 3 summarizes the total power generated from the solar cells (sail and rover) and from wind energy (propulsion).

Table 3. Available Power

\begin{tabular}{|c|c|}
\hline Power Source & $\begin{array}{c}\text { Power Generated } \\
\text { (W) }\end{array}$ \\
\hline Sail & 13.65 \\
\hline Rover & 0.07 \\
\hline Propulsion & 1.8 \\
\hline TOTAL & $\mathbf{1 5 . 5 6}$ \\
\hline
\end{tabular}

Power generated from solar cells can be stored in batteries as charged energy for a long period of time in order to meet power requirements. If 24 hours are allowed for charging, approximately $330 \mathrm{~W}$-h of energy can be stored and used for almost 11 hours of either science missions or mobility.

\section{B. Wind Turbine Design}

The turbine-powered rover (Figure 1) uses a two-bladed rotor to capture kinetic energy in Venus surface winds. This energy is converted to electrical energy via a high temperature generator. While Venus surface conditions present serious challenges for generator function, high-temperature motors suitable for operation at Venus surface conditions have been developed. ${ }^{19}$ This design could be modified to run backwards as a generator. Electrical energy produced would be stored in sodium-sulfur batteries, which can operate at Venus surface temperatures. ${ }^{20}$ This energy would then be used to power science instruments and drive the wheels via a high temperature motor.

The power generation of the turbine will be dependent on the power of the air incident upon the turbine disk area. The total kinetic power of this air is given as:

$$
P=\frac{1}{2} \rho V_{\text {wind }}^{3} A
$$

For a sail, the theoretically extractable power is considerably less than the total kinetic energy of the air, as given by the Betz limit seen in Eq. (4). Furthermore, unavoidable inefficiencies in the rotor will significantly reduce actual power production.

Rotor efficiency will have a large impact on the power output of the rover, and it is necessary to estimate the efficiency of a turbine operating in Venus surface conditions. It is not immediately obvious how well performance analyses for large commercial turbines operating on Earth will apply to a small wind turbine operating in a highdensity atmosphere. However, in terrestrial wind turbines, efficiency is approximately linear with lift/drag ratio, ${ }^{21}$ and lift/drag ratio is correlated to the turbine's Reynolds number, as seen in Fig. 5. 


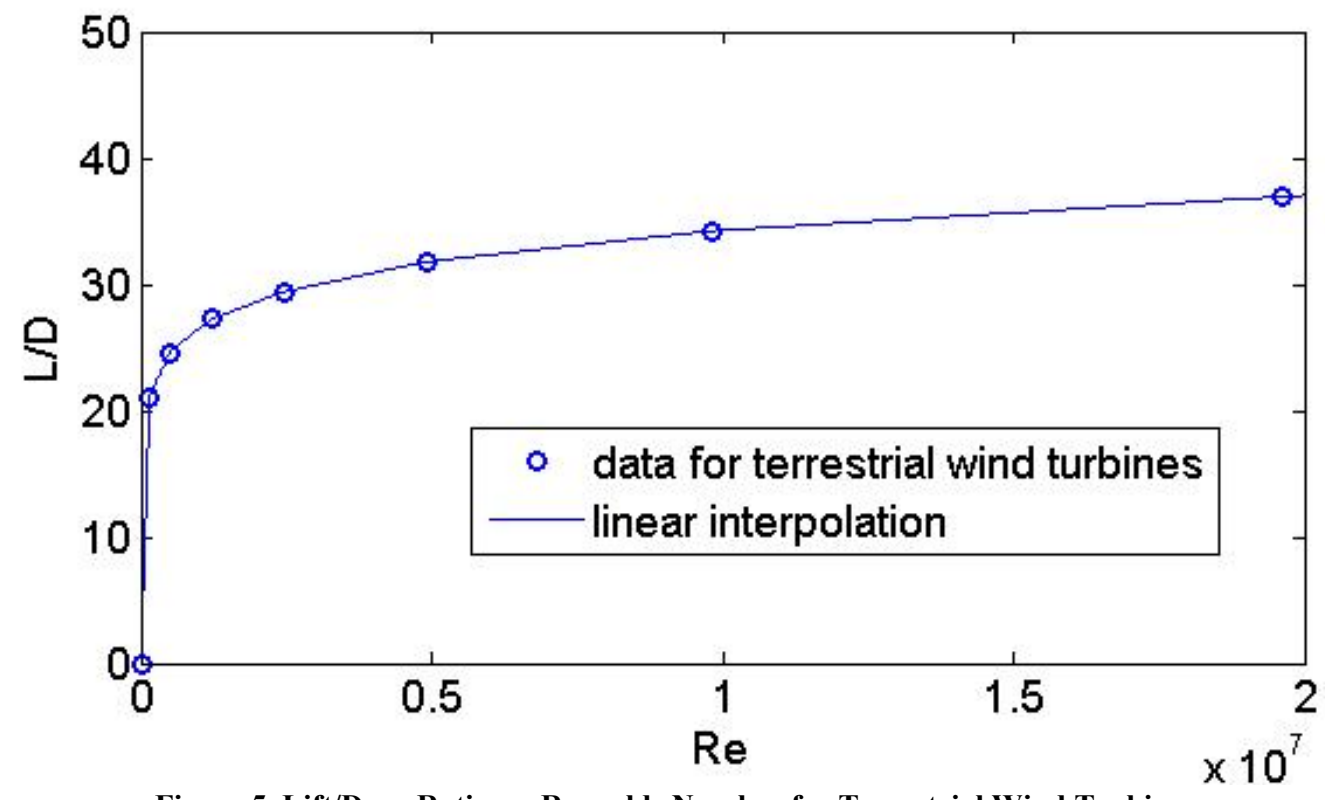

Figure 5. Lift/Drag Ratio vs. Reynolds Number for Terrestrial Wind Turbines

The Reynolds number gives the ratio of inertial to viscous forces, and is defined as:

$$
R e=\frac{\rho V_{a p p} L}{\mu}
$$

Since the rotor may be moving much faster than the wind speed, we can no longer approximate the apparent wind speed as equal to the wind speed. Apparent wind velocity $\mathrm{V}_{\text {app }}$ and characteristic length $\mathrm{L}$ are both design variables of the rotor. ${ }^{21}$ The apparent wind velocity depends on tip speed ratio, which is defined as:

$$
T S R=\frac{V_{\text {blade }}}{V_{\text {true }}}
$$

Tip speed ratio is tied to rotor efficiency, ${ }^{22}$ as shown in Fig. 6:

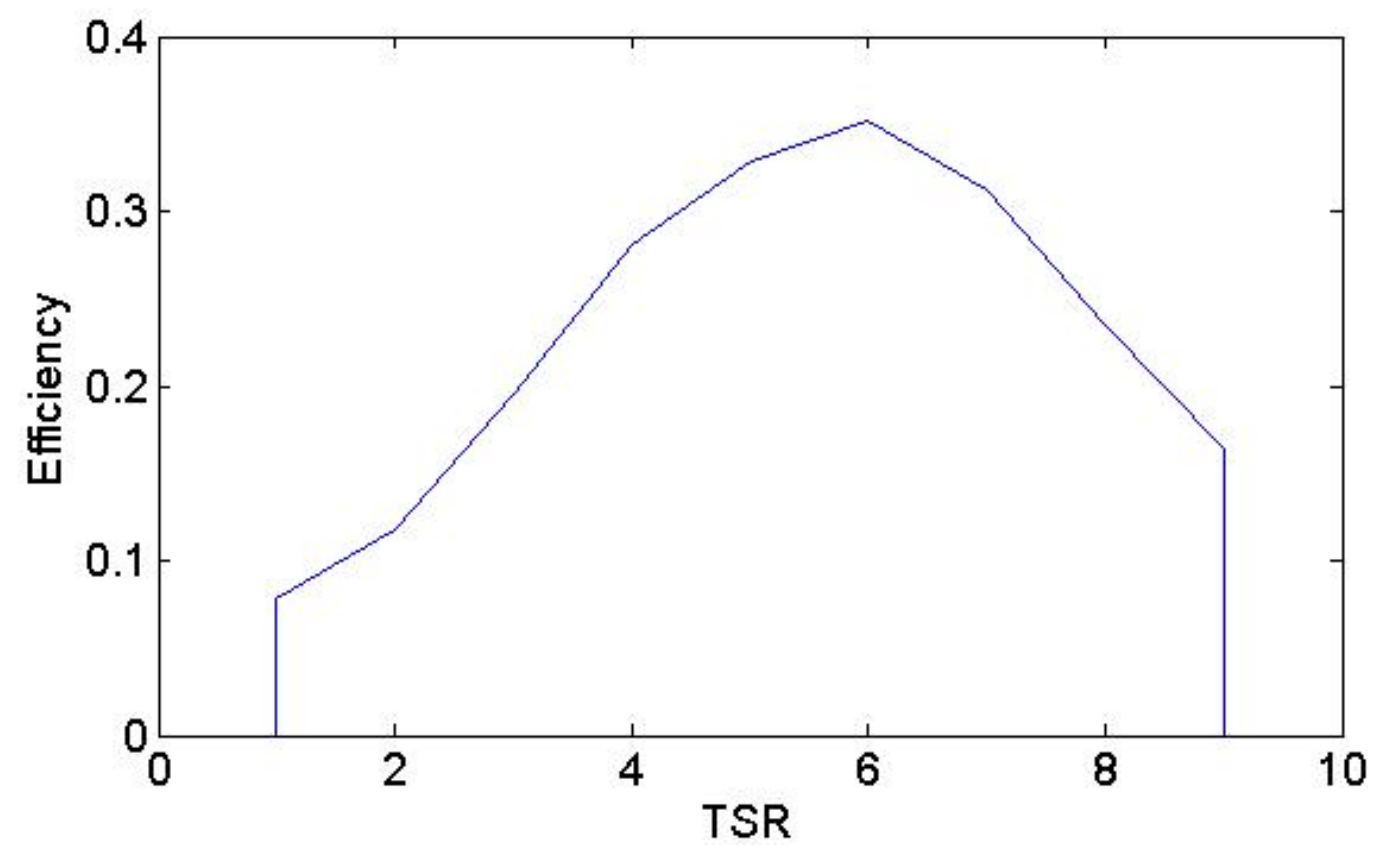

Figure 6. Efficiency as a Function of Tip Speed Ratio (TSR) for a Two-Bladed Rotor

Peak efficiency is achieved when TSR is approximately 6.3. Using a design wind speed of $0.6 \mathrm{~m} / \mathrm{s}$ and design TSR of 6.3 gives a design apparent wind speed of $3.8 \mathrm{~m} / \mathrm{s}$ 
The characteristic length $\mathrm{L}$ for the rotor blades will depend on solidity, defined as:

$$
\text { Solidity }=\frac{A_{\text {blades }}}{A_{\text {rotor cross section }}}
$$

For a two-bladed configuration, terrestrial wind turbines have efficiency optimized when solidity is $\sim 0.05 .{ }^{21}$ Setting solidity equal to 0.05 and using the relationships detailed above reduces turbine efficiency to a function of rotor area. This allows for calculations of energy stored for a given wind speed as seen in Fig. 8.

The mass is estimated by summing the estimated mass of the turbine tower, blades, and generators. For a given height, the mass of a tower varies with the square of tower height. Based on known values for terrestrial turbine tower masses, the approximate mass of the mast for a Venus wind turbine can be interpolated: ${ }^{23}$

$$
m_{\text {tower }}=3.64 h^{2}
$$

To leave room for blade clearance of science instruments while keeping the center of pressure low, the tower is assumed to have a height $30 \mathrm{~cm}$ greater than the rotor blade length.

Rotor blade mass scales approximately with the radius raised to the 2.3 power. ${ }^{24}$ Using a scaling factor of 1.63 based on terrestrial wind turbine data, ${ }^{24}$ blade mass can be approximated as:

$$
m_{\text {blades }}=n * 1.63 r^{2.3}
$$

Generators are estimated to weigh $0.88 \mathrm{~kg}$ each, based on the mass of a demonstrated high-temperature motor. ${ }^{25}$

When combined, these three components will compose the bulk of the turbine weight and allow for estimation of turbine mass as shown in the blue curve in Fig. 7.

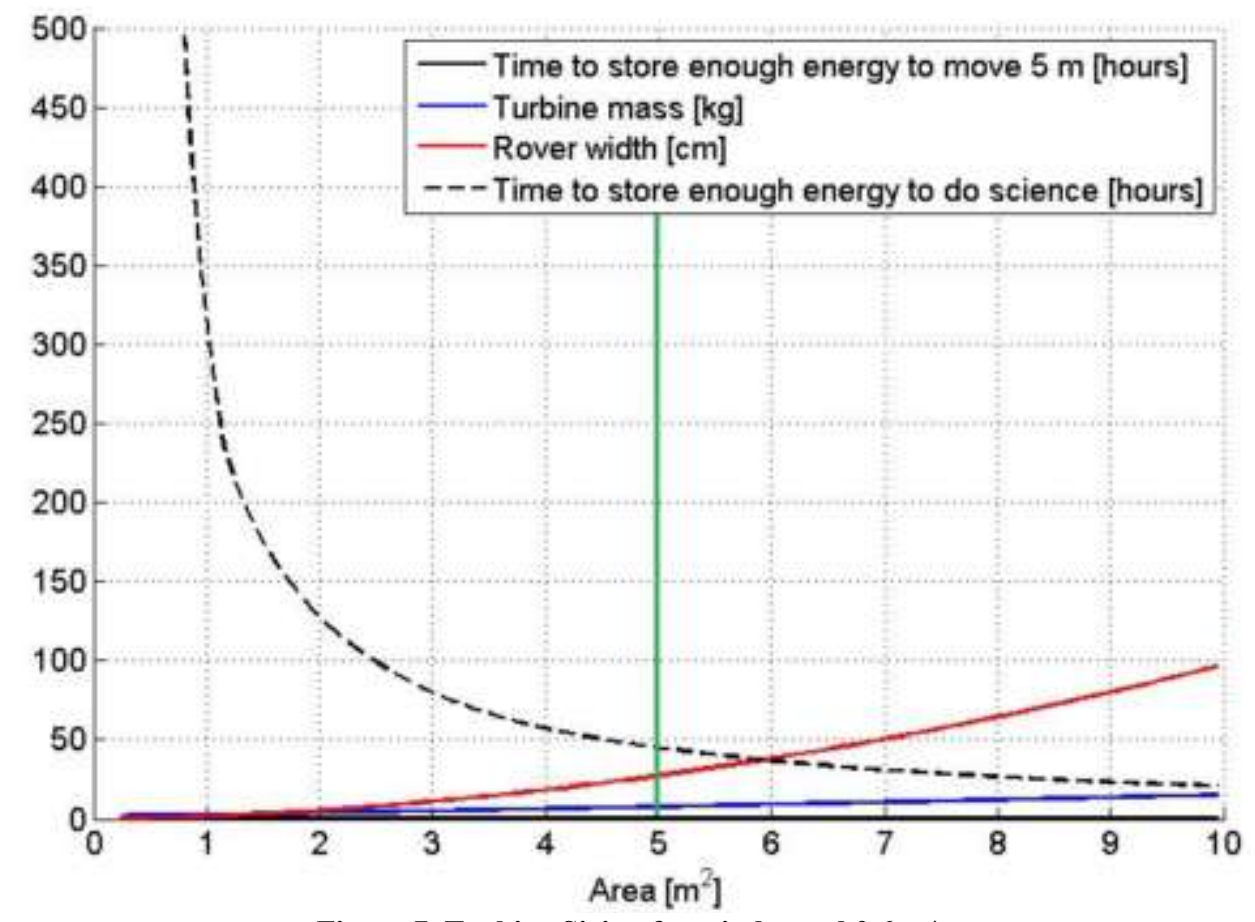

Figure 7. Turbine Sizing for wind speed $0.6 \mathrm{~m} / \mathrm{s}$

Power production is directly dependent on turbine area and a large-sized turbine has the obvious advantage of providing more power to the rover. However, constraints on mass and packaging make it necessary to keep turbine size relatively small. Using the methods detailed above to estimate rover size, it seems likely that $5 \mathrm{~m}^{2}$ turbine area will provide the appropriate balance. At this baseline area of $5 \mathrm{~m}^{2}$ and give $0.6 \mathrm{~m} / \mathrm{s}$ winds, the turbine will generate 5.2 Watts. Thus, it will take 80 seconds to store enough energy to move 5 meters, and 45 hours to store enough energy to do one science run.

Assuming wind speed on the Venus surface to lie in the (relatively wide) range of 0.3 to $0.9 \mathrm{~m} / \mathrm{s}$, we perform the analysis varying wind speed while holding area constant at $5 \mathrm{~m}^{2}$, to give the results in Fig. 8 .

At the low end of the wind speed range, the turbine will produce $0.59 \mathrm{~W}$, take about 12 minutes to store enough energy to move, and take $\sim 17$ days to store enough energy for one science run. This shows that the $5 \mathrm{~m}^{2}$ turbine will provide enough power for mission success even in the lowest wind speeds considered. Equally importantly, the turbine will not tip the rover even at the highest wind speeds. 


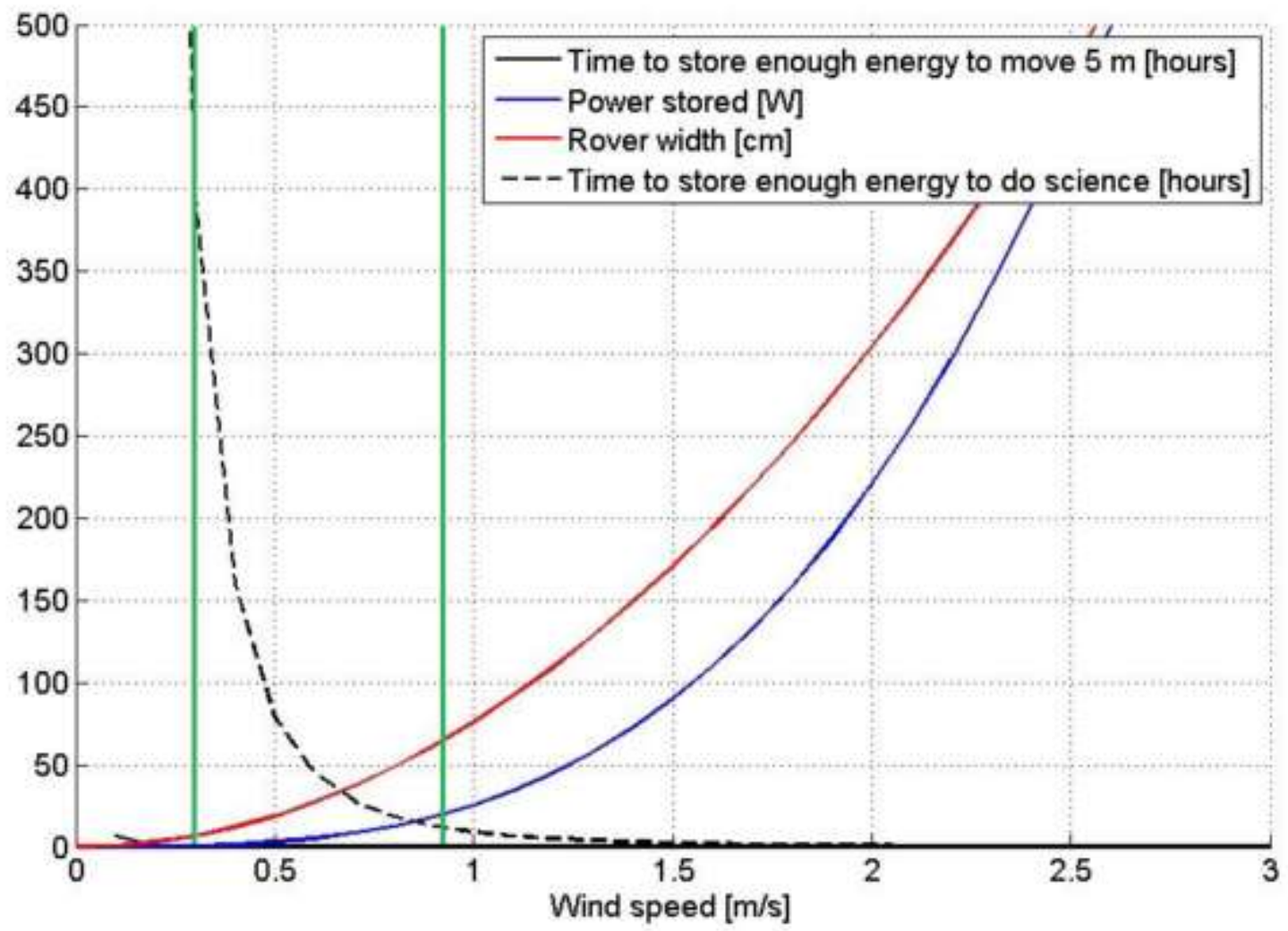

Figure 8. Analysis of a $5 \mathrm{~m}^{2}$ Turbine

\section{Trade Studies and Down-Select}

Both Venus rover concepts have their advantages and disadvantages. The landsailer is simpler - it has fewer moving parts and is overall less massive - and it has greater aesthetic appeal. However, the motor actuating the mast would lack precision control and the rover would be difficult to package; the mast would need to be deployable. In addition, if the unpredictable wind speeds on the Venusian surface causes the vehicle to tip, the mission is compromised.

The wind turbine rover is much easier to control with finer precision motors, easier to pack, takes advantage of higher wind speeds to generate a greater amount of power, and is less likely to tip. Its main disadvantage is the higher complexity required (more moving parts). It is also more massive than a landsailer and would require a longer charging time for lowest expected wind speeds (on the order of weeks).

Due to the lower risk, the wind turbine was selected as the Venus rover design concept for this study.

\section{Candidate Science Payload}

The designed mission for the Venus rover is to carry a payload of science instrumentation to the surface, and the detailed design of the mission will depend on the science payload selected. Although designing scientific instruments for the Venus surface is not part of this study, a notional payload is required to enable the rover design requirements to be established. Thus, the science package listing here should not be considered the "final" payload selection, but rather a notional set of payload instruments representative in overall function to what would be selected for an actual mission. The instrument set here is based on past instruments flown to Mars, with the objective that the capabilities of this mission would be similar in scope to the scientific mission performed by the MER rovers.

The amount of power available is limited. To be able to get the most out of Venus's wind speed, a low-mass, low-power payload is necessary for the rover. This was a significant factor in the instrument set selected here. The candidate scientific instrument list is shown in Table 1. Several other instruments were considered, but were removed from the list due to higher mass or power than the design goal required. The resulting instrument list contains instruments that image the site, measure the chemistry and mineralogy of the surface, and grind or drill samples that will be taken from Venus's surface, as well as measure temperature, pressure, and wind speed and direction. 
Table 1. Candidate Instrument List

\begin{tabular}{|c|c|c|c|c|c|}
\hline Instrument & $\begin{array}{l}\text { Mass } \\
(\mathrm{kg})^{5} \\
\end{array}$ & Power $(\mathrm{W})^{5}$ & Size $(\mathrm{cm})$ & $\begin{array}{c}\text { Bits per } \\
\text { Measurement }\end{array}$ & $\begin{array}{c}\text { Operating } \\
\text { Temperature }\left({ }^{\circ} \mathrm{C}\right) \\
\end{array}$ \\
\hline $\begin{array}{l}\text { Alpha Particle X-Ray } \\
\text { Spectrometer (APXS) }\end{array}$ & 0.5 & 2.5 & $\begin{array}{l}8.5 \text { long, } \\
5 \text { diameter }\end{array}$ & 12,288 & -40 to 5 \\
\hline Calibration Target & 0.1 & 0 & $10 \times 10$ & - & - \\
\hline X-ray Diffraction (XRD) & 5 & 15 & $30 \times 20 \times 10$ & $2,793,600$ & Optimal: -60 \\
\hline Microscopic Imager & 0.2 & 5 & $12 \times 7.5 \times 5$ & $8,388,608$ & $\begin{array}{c}\text { Operating: }-55 \text { to } 20 \\
\text { Non-Operating: }-110 \text { to } 50\end{array}$ \\
\hline $\begin{array}{l}\text { Thermal } \quad \text { Emission } \\
\text { Spectrometer (TES) }\end{array}$ & 2.4 & 5.6 & $\begin{array}{c}23.5 \times 16.3 \times \\
15.5\end{array}$ & $10,567,680$ & -45 to 50 \\
\hline Navigation Cameras & $.2 \times 4$ & 2 & $5 \times 5 \times 10$ & $8,388,608$ & CCD: -55 to 20 \\
\hline PanCam & $.27 \times 2$ & 3 & $50 \times 60 \times 110$ & $8,388,608$ & $\begin{array}{l}\text { Operating: }-55 \text { to } 20 \\
\text { Non-Operating: }-110 \text { to } 50\end{array}$ \\
\hline Radar Reflector & 1 & 0 & $50 \times 50 \times 20$ & - & - \\
\hline Radiant Heater (Mini-TES) & 2.3 & 45 & $10 \times 10 \times 10$ & 0 & - \\
\hline $\begin{array}{l}\text { Rock Abrasion Tool (RAT) } \\
\text { - ARM (IDD) }\end{array}$ & 0.7 & 10 & $\begin{array}{l}10 \text { long, } \\
7 \text { diameter }\end{array}$ & 3,600 & $0-500$ \\
\hline $\begin{array}{l}\text { Rover Environmental } \\
\text { Monitoring Station }\end{array}$ & 1.2 & $50 \mathrm{hrs}$ & $10 \times 10 \times 10$ & 300 & -130 to 70 \\
\hline
\end{tabular}

A significant constraint on the instrument design for the rover is the high surface temperature. The candidate instrument listed are primarily designed to work at temperatures of $20^{\circ} \mathrm{C}$ and below. Since thus rover is not designed with a cooling system, it is assumed that by the time this mission is ready to launch, high-temperature electronics will be available, allowing instruments of similar capability to withstand the extreme Venusian surface temperatures. To account for the fact that these instruments will be of different design, a growth factor of $150 \%$ was assumed on the mass and power values shown in table 1 .

Atmospheric science requirements include data on surface pressure, temperature, and wind speed and direction. These will be measured using a Rover Environmental Monitoring Station (REMS) instrument similar to that used on the MSL mission to Mars, incorporating a series of booms containing different sensors to measure meteorological data. ${ }^{26}$

The Alpha Particle X-Ray Spectrometer (APXS) is typical of instruments to measure the elemental composition of samples. This is done by analyzing the energy spectrum of the characteristic fluorescent X-rays emitted when a sample is irritated with alpha particles from radioactive source..$^{27,28,29}$ While existing sensors for Energy-dispersive $\mathrm{X}$-ray detectors used in an instrument such as this achieve low noise levels only when operating at low temperature, the noise floor in a detector is an exponential function of the temperature divided by the bandgap of the semiconductor used for the detector (typically a p-i-n diode operating at high reverse bias). Thus, the basic physics implies that by using a wide-bandgap semiconductor for the detector, an acceptable noise level can be achieved at Venus temperature. Although such high-bandgap avalanche photodiodes are not currently being manufactured, there is no fundamental reason that they could not be developed.

A Thermal Emission Spectrometer (TES) is typical of a non-contact measurement. TES is a Fourier Transform Spectrometer that will provide remote measurements of mineralogical as well as thermophysical properties of its surface surroundings. An example of the effective operation of thermal emission spectroscopy on a planetary rover is the use of the miniTES instrument on the Mars Exploration Rovers. ${ }^{30}$ Infrared detectors (bolometers) can operate at the required temperature, however, to function, the instrument needs to be at a lower temperature than the sample being analyzed. Due to Venus's greenhouse effect, objects in equilibrium at the surface are at nearly the same temperature, meaning the sample will be about the same temperature as the instrument. For the Venus instrument, a radiant heater will be used instead to heat the sample for the necessary temperature difference. The radiant heater

${ }^{5}$ Adjusted. 
will be a simple metal halide lamp similar to those used on submersible vehicles. ${ }^{8}$ These are rated to a depth of 2,000 meters under water, corresponding to a pressure of roughly twice the Venus surface. The heated sample will emit a unique thermal infrared spectrum, characteristic of the different minerals contained in the sample. ${ }^{30}$

A third composition and mineralogy tool that could be used on such a rover is an X-ray diffraction tool. An example of an X-ray diffraction instrument is the CheMin package used on the Mars Science Laboratory to analyze the crystallographic composition of samples. ${ }^{31}$ The CheMin expose a beam of X-rays to a sample of rock, and the $\mathrm{x}$ ray diffraction pattern reveals the crystal structure of the sample. Each mineral has a specific diffraction pattern which is identified by the angular dependence of the diffracted beams.

One of the desired objectives of a surface science investigation is that the soil and surrounding rocks be studied. A Rock Abrasion Tool (RAT) ${ }^{32}$ will be used so that the analysis tools can be used to investigate the chemical composition and mineralogy of not only surface samples, but also soil that is not immediately exposed to the Venusian atmosphere, as well as the insides of rocks. The RAT will position itself against a rock or soil surface using the rover's arm it is positioned on, and use a grinding mechanism to dig into the rock to expose a fresh sample that has not been exposed to the Venusian atmosphere. Once pristine surface is exposed, the APXS, mini-TES. and $\mathrm{X}$-ray diffraction instruments can be employed to determine the mineralogy of samples not immediately exposed to the Venusian atmosphere. Adaptation of the Rock Abrasion Tool to operation on Venus requires use of hightemperature motors; an abrasion and coring tool for Venus is currently being developed, ${ }^{33}$ and a drill to has been developed and demonstrated in operation on the surface of Venus by previous Russian missions. ${ }^{5}$

Imaging investigations are also important. A Microscopic Imager (MI ${ }^{34}$ will be used to take close-up, highresolution images of rocks and surface soil. As it is placed on the rovers arm, used in conjunction with the RAT, the MI will have the capability to take images of subsurface samples as well. Close up images of the Venusian surface will be useful for studying the microstructure of rocks and soil. The Panoramic Camera, or PanCam for short, will take high-resolution panoramic images of the surface. ${ }^{35}$ Images taken by PanCam would be useful in identifying potentially interesting sampling sites, while the Navigation Cameras ("NavCams") ${ }^{36}$ will take wider field-of-view images to be used to direct the rover driving. Images provided from NavCam as well as PanCam will also provide data for investigative studies of surface morphology, rock and soil distribution, as well as the general surface geology. A calibration target will also be placed on the surface of the rover in view of the cameras, to provide a reference for the cameras to calibrate images to the Venus illumination spectrum, so that the data taken on Venus can be compared to data taken on Earth. Finally, the radar reflector is an unpowered instrument that will be used to allow the rover to be located, either from a radar in an orbiting satellite, or directly from Earth.

\section{Turbine-Powered Rover Detailed Design}

\section{A. Mission Requirements}

To this date, spacecraft that have been sent to Venus include orbiters, atmospheric probes, stationary landers, and balloons, but a rover has yet to be sent to explore Venus. The goal of this project is to analyze a conceptual design for a rover to be sent to, and survive, the extreme conditions of the Venus surface. Due to these extreme surface conditions, the longest a lander or probe has ever lasted is the Venera 13 for 127 minutes. The short mission times mean that not much has been able to be studied on the surface first hand. This mission is designed to verify assumptions based off the small amounts of data gathered from previous probe or lander missions, as well as uncover entirely new data. Though the past probes to reach the surface of Venus have made advances over what was known before them, a rover would be next level of discovery for Venus. Not only would one spot be able to be studied, but several meters of area surrounding the landing site.

It is possible that the top layers of soil and outside of rocks are affected by the chemicals in the atmosphere. By studying the lower layers of soil and the insides of rocks, the rover will be able to study samples that have been untouched by the Venusian atmosphere for hundreds, or potentially even thousands of years. This will probe the geological history of Venus, and determine the state of alteration of the mineralogy due to surface/atmospheric interaction, and possible even shed light on the intriguing question of whether Venus ever had water on its surface, and when (or if) the global climate had altered to its current state as a planet of extreme surface conditions.

\section{B. Concept of Operations}

Atmospheric entry and descent through the Venus atmosphere have been previously done by NASA with the Pioneer Venus mission atmospheric probes. ${ }^{37}$ This mission assumes planetary entry will be performed with a direct atmospheric entry using a 4.5 diameter aeroshell containing a heat shield on the bottom and a parachute system in 
the top compartment. Upon atmospheric entry and deceleration, the heat shield will drop and the spacecraft will slow down through the deployment of a drogue parachute followed by another high-temperature parachute.

The rover is assumed to land directly on its wheels, similar to the design in a previous study; ${ }^{8}$ however, landing analysis or simulations were not conducted to validate the feasibility of the suspension system's ability to absorb the shock upon landing. There is no "typical" surface terrain to select on Venus; its diverse surface features include, "mountain ranges, craters, continent-spanning sinuous hills, and chaotic terrain." However, it is expected that a highly sloped or extremely rugged landing site can be avoided and that the terrain will be relatively flat upon landing. Surface roughness may be estimated from images obtained by the Russian Venera landers, ${ }^{38}$ as shown in Fig. 9.
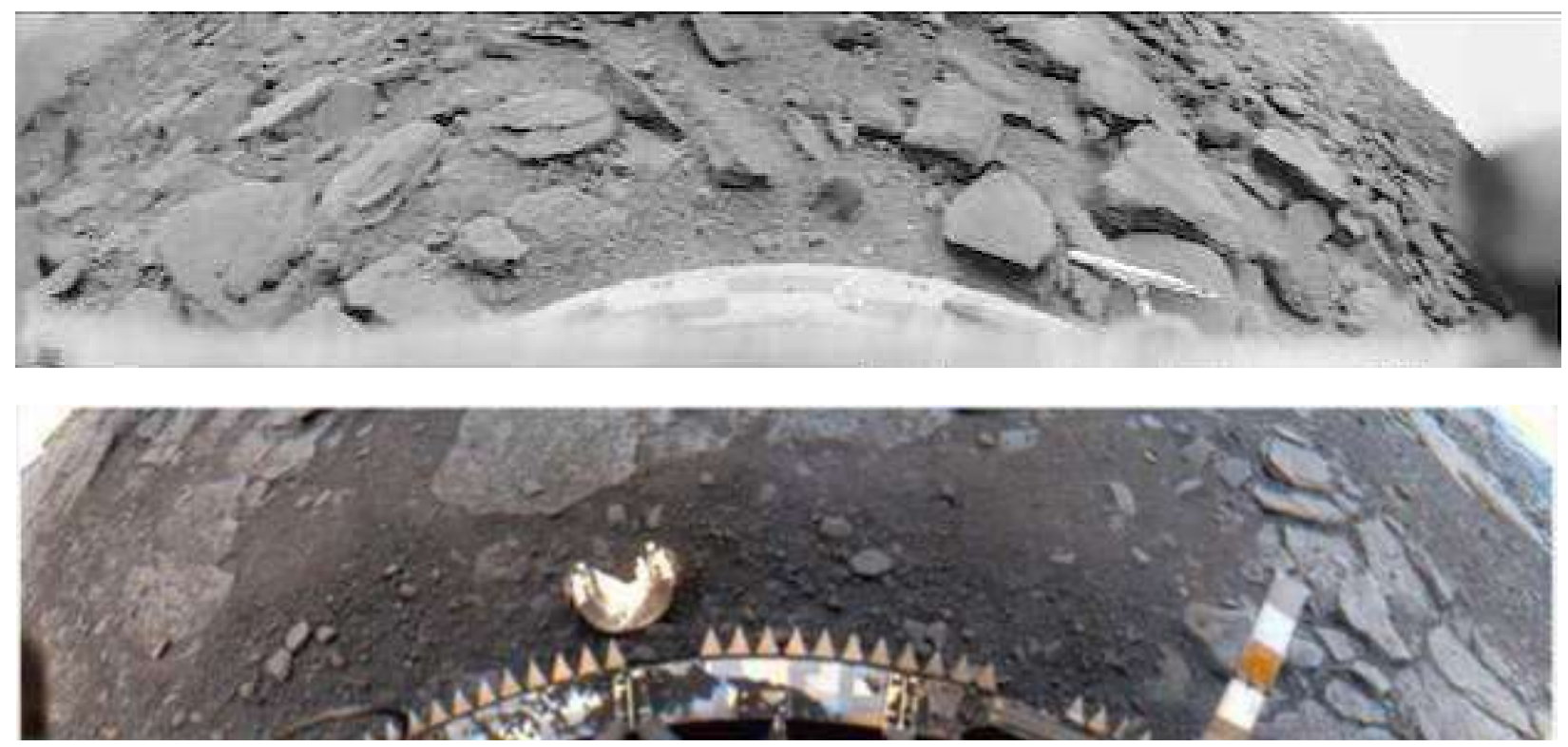

Figure 9. The surface of Venus, as viewed from Venera-9 (top) and Venera-13 (bottom) landers

The Venusian solar day lasts approximately 116.75 Earth days, ${ }^{39}$ so about 58 days of sunlight can be achieved per day. Although the rover does not require sunlight for operation, since it is wind and not solar powered, illumination is required for vision, and hence the mission will be designed to operate only during the daylit portion of the Venus day. The mission duration was assumed to be 55 days, during with time all scientific operation and data transmission back to Earth is to be accomplished. Under worst-case expected conditions of $0.3 \mathrm{~m} / \mathrm{s}$ wind speeds, the rover will need to charge for approximately 17 days between science runs, enabling for a total of 4 science runs. Average-case conditions of $0.6 \mathrm{~m} / \mathrm{s}$ wind speeds enables for 19 mission science runs with two days of charging time in between each run.

\section{Wind Turbine Detailed Design}

Initial analysis assumed that the rotor and generator would both operate at their maximum efficiencies; however, because of the uncertainty regarding Venus surface conditions as well as some variation in wind speed being likely, this is unworkable without the use of a variable gear ratio or voltage control of the generator. Both of these techniques would require significant addition of moving parts and therefore complexity to the rover, which would increase the risk of mission failure. To avoid this risk, three different generators will be used, each of which will have a fixed gear ratio and voltage. Relationships between torque, RPM, and efficiency are based on fixed gear, constant voltage assumptions ${ }^{40}$ and values for the high-temperature motor ${ }^{25}$ and can be seen in Fig. 10.

By switching between these generators, the rover will be able to maintain a tip speed ratio, torque, and RPM, which will keep both the rotor and generator within acceptable operating limits over the required range of wind speeds. 


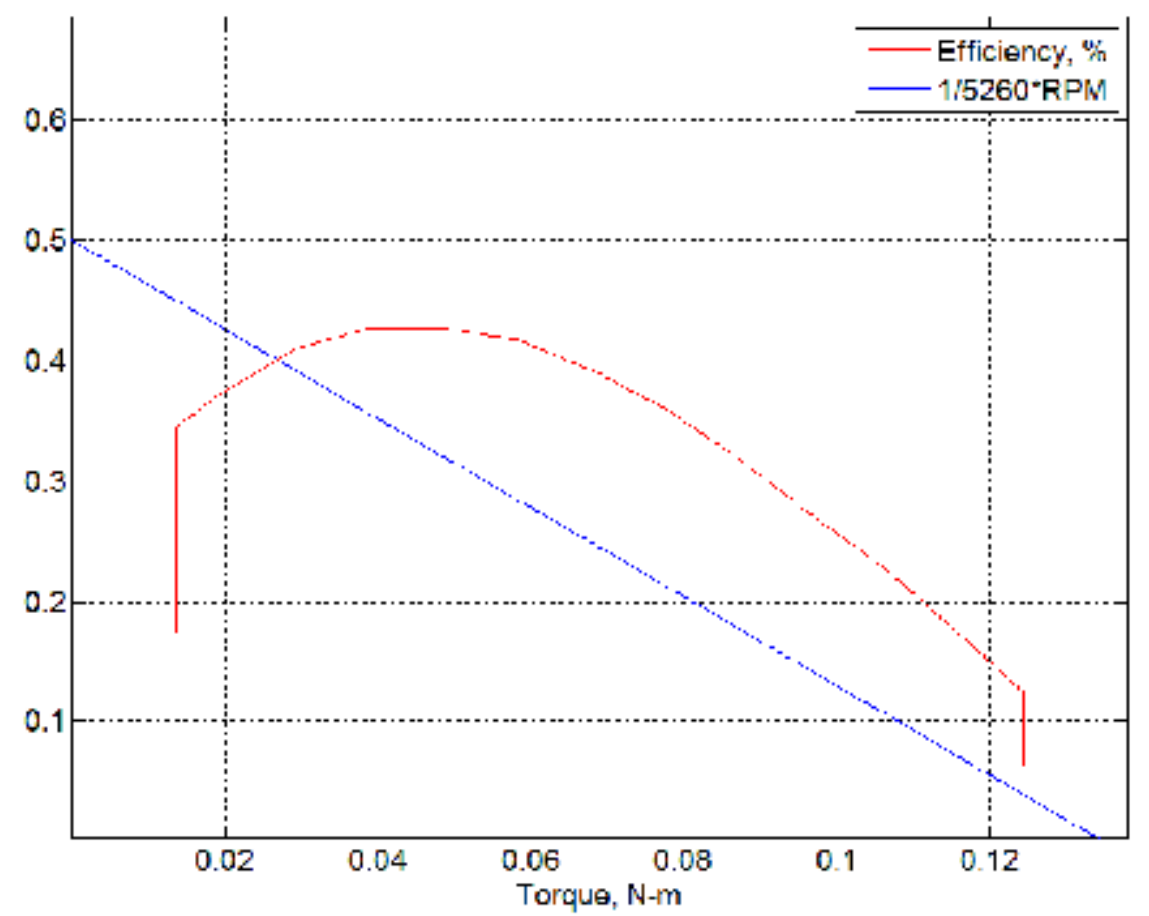

Figure 10. RPM and Efficiency as Functions of Torque for a Constant Voltage Generator

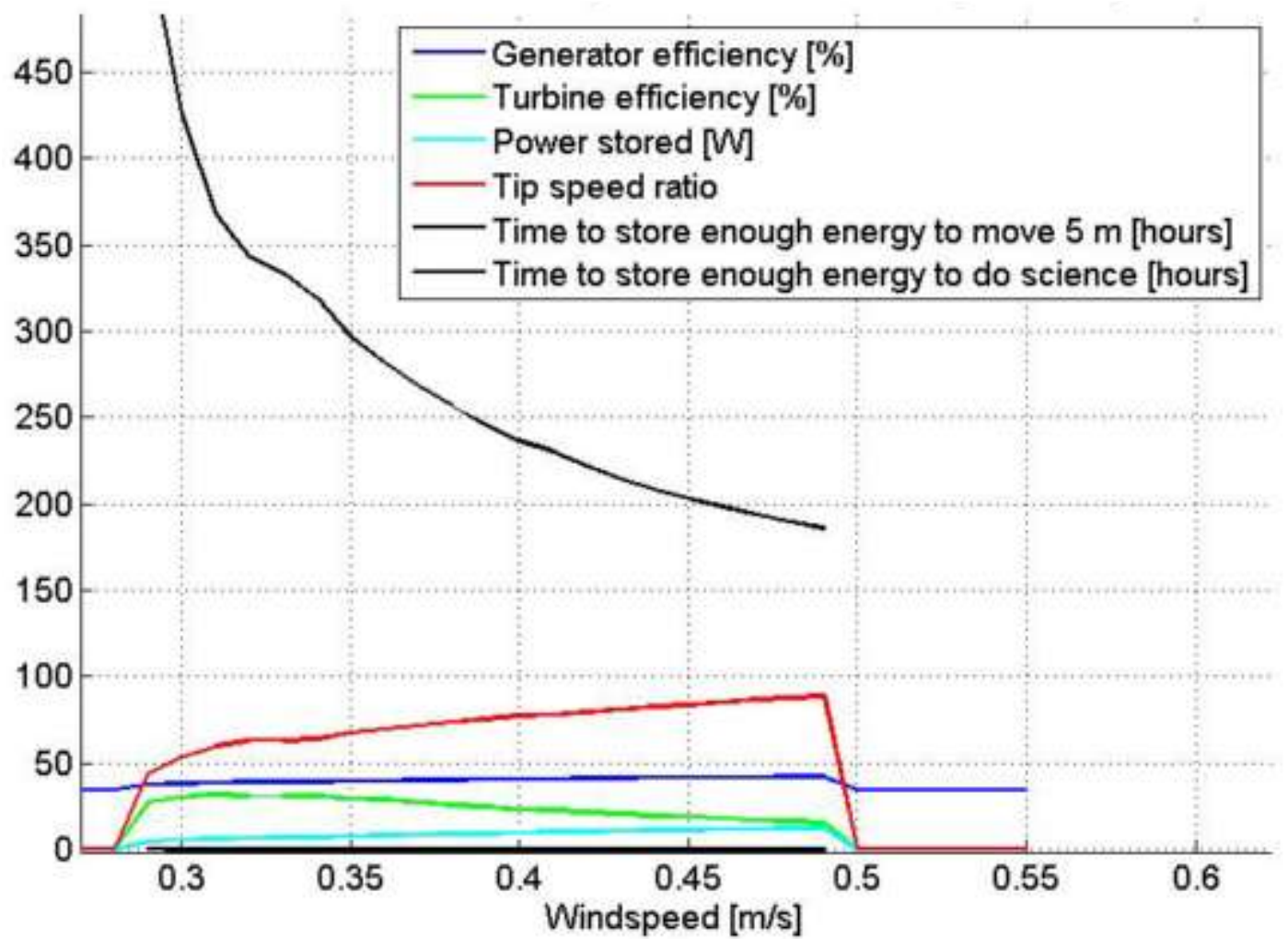

Figure 11. Analysis of efficiency, power stored, tip speed ratio, and time to store energy for Generator \#1 (low wind speed) 


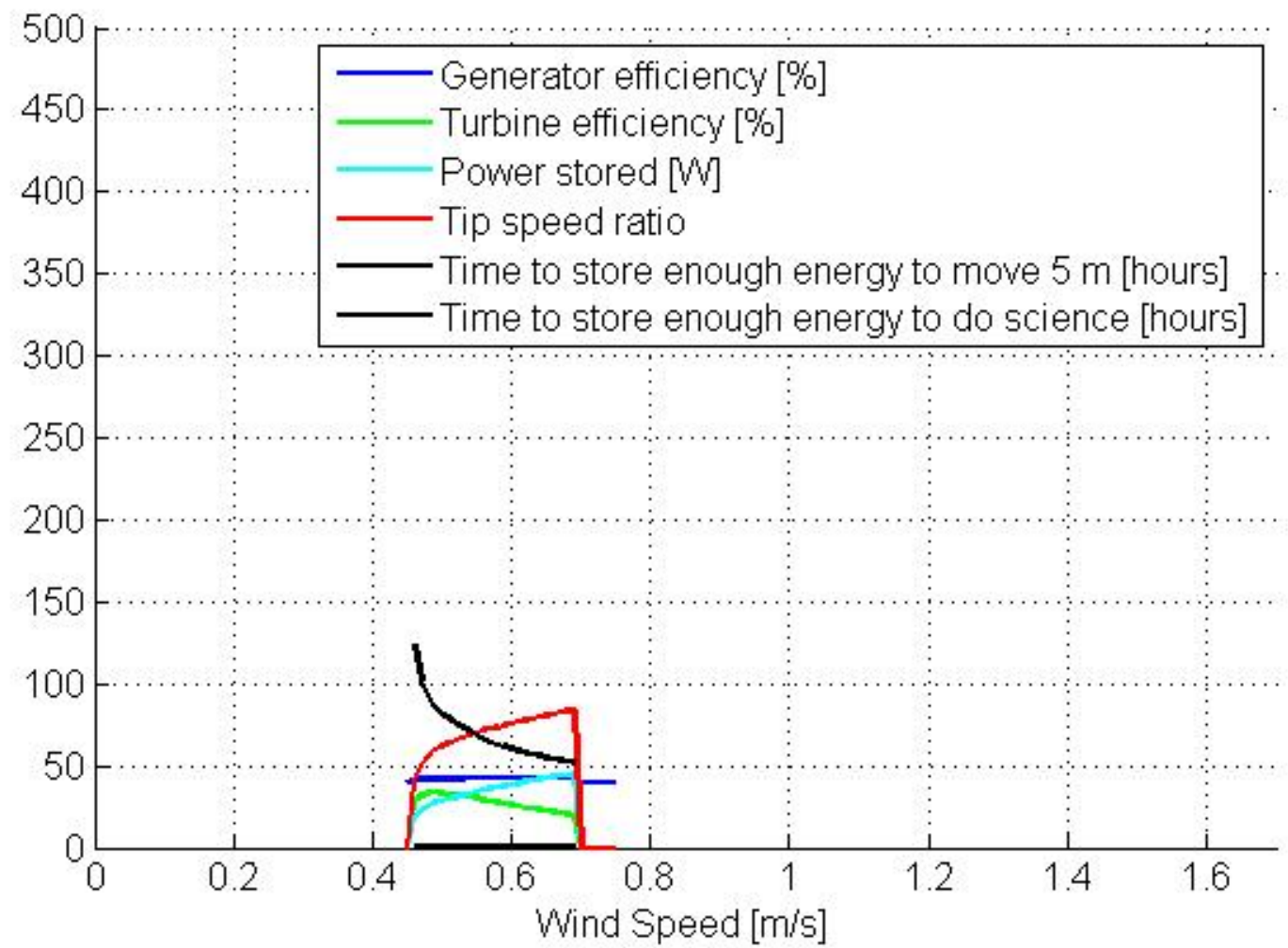

Figure 12: Analysis of efficiency, power stored, tip speed ratio, and time to store energy for Generator \#2 (intermediate wind speed)

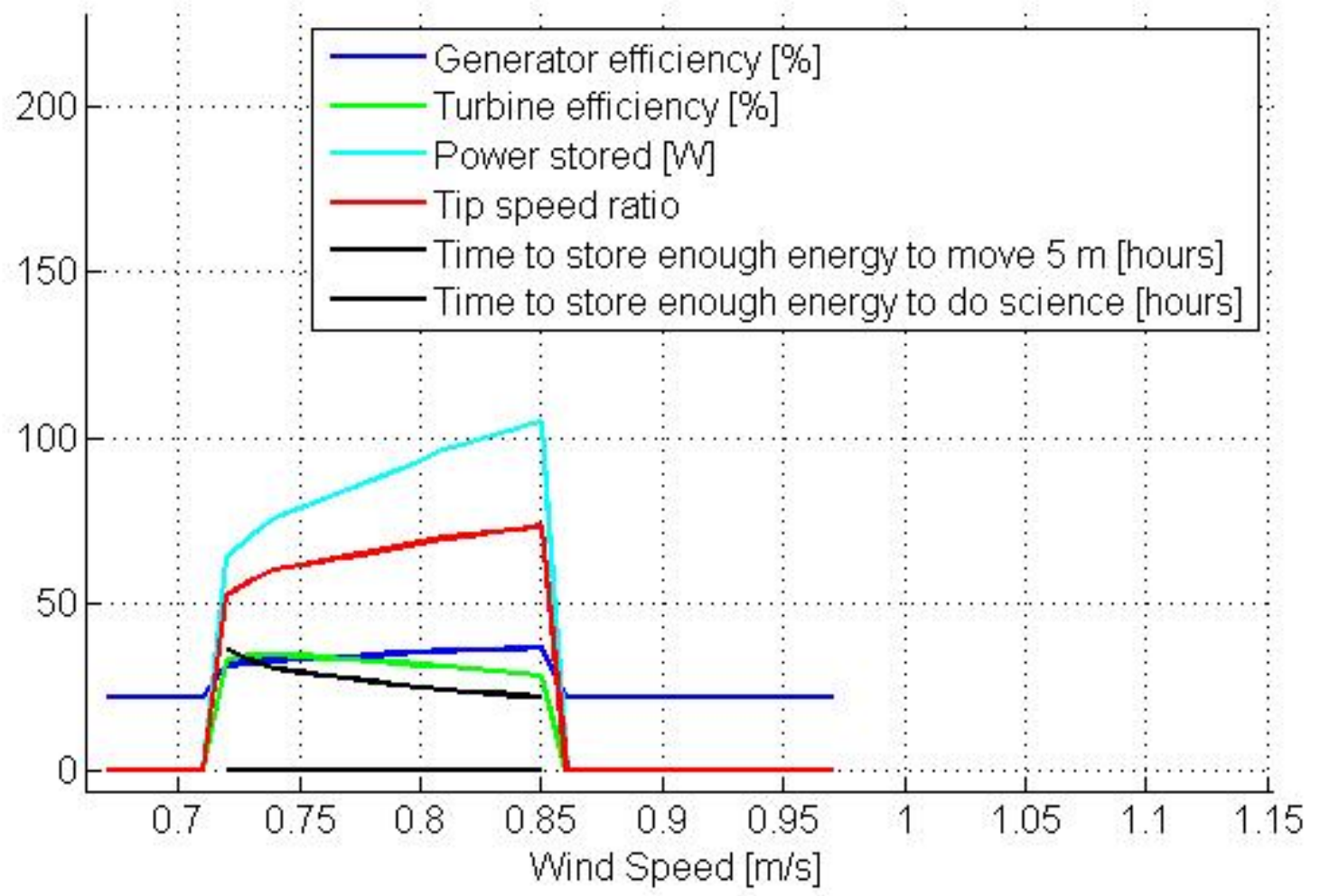

Figure 13: Analysis of efficiency, power stored, tip speed ratio, and time to store energy for Generator \#3 (high wind speed) 


\section{Rover Mechanical and Subsystem Design}

\section{A. Four-Wheel vs. Six-Wheel Design}

Trade studies were conducted to determine the most feasible design for the rover body configuration. The ability of the rover's mobility system to traverse obstacles and its steering mechanism are major elements that characterize the rover. Two types of suspension systems in particular were investigated for this mission: four-wheel suspension and six-wheel rocker-bogie suspension systems.

Four-wheeled suspension systems use differential steering to change direction and require few motors for actuation. The rocker-bogie suspension systems consist of two links, a main rocker, and a forward bogie on each side, as illustrated in Fig. 14 (right). A wheel and steering mechanism is attached to one end of the main rocker while the opposite end is connected to the forward bogie through a passive pivot joint. Weight is distributed on the wheels by defining rocker and bogie lengths as well as pivot joint positions. ${ }^{41}$

Rovers capable of surmounting large obstacles in comparison to wheel size have a high degree of mobility. Enough traction is required from the rear wheels to thrust the forward wheels with enough force to overcome an obstacle. Four-wheeled rovers are typically incapable of traversing obstacles larger than the wheel radius due to lack of traction while six-wheeled rovers are able to surmount these obstacles head-on because the extra wheels provide greater traction and reduce the normal force on each wheel. Rocker-Bogie suspension systems can also perform multiple types of steering (Ackerman, crabbing, differential, and zero radius) for greater mobility. ${ }^{41}$

Although the limited amount of traction is an issue for a four-wheeled rover design, the rover is still able to overcome obstacles if the obstacle is approached at an angle and traversed one wheel at a time. This enables the four-wheel design to have similar capabilities to the six-wheel design but with fewer control system requirements, less suspension mass, and less actuation motors, which greatly reduces the weight and complexity of the system and fits better within the scope of a Discovery-class mission. Furthermore, the rocker-bogie suspension system carries the risk of jamming an obstacle between the tandem wheels of the bogie.
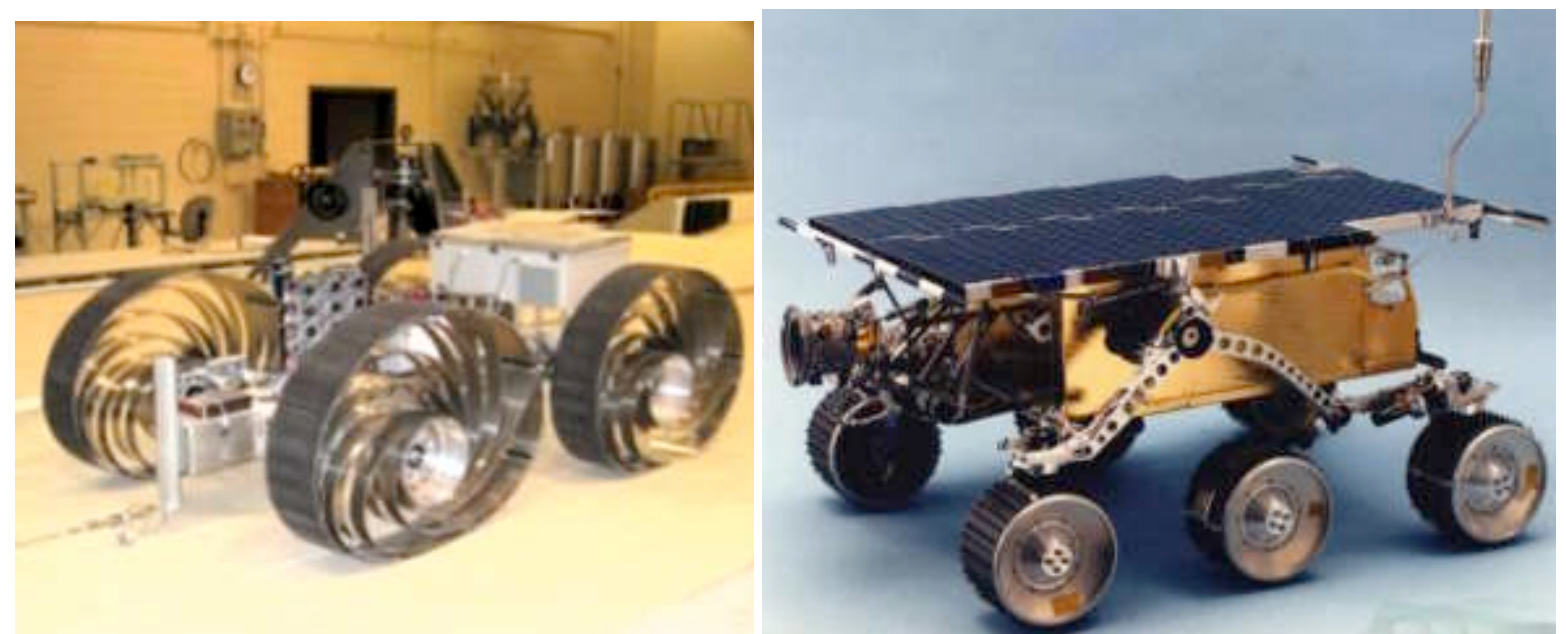

Figure 14. Four-Wheeled rover (left) and Six-wheeled Sojourner rover with rocker-bogie suspension (right)

\section{B. Wheel Sizing and Drive Train Configuration}

The diameter of the wheel is proportional to the size of the obstacle, and for a four-wheeled vehicle, it can be estimated that the rover can overcome an obstacle roughly $18 \%$ of its wheel diameter. If an average obstacle size of 15 centimeters tall is assumed on the surface of Venus, the minimum wheel diameter required to traverse these obstacles is approximately 0.833 meters.

Two different drive train configurations were investigated for this concept: a dual-output angle drive and a standard four-wheel drive, as shown in Fig. 15. The dual-angle output drive concept is simpler and uses only two motors for mobility, whereas the standard four-wheel drive would have a motor to power each wheel. However, the simpler drive-train configuration can only accommodate one mode of steering (skid steering) ${ }^{41}$ and therefore not selected for the design. 

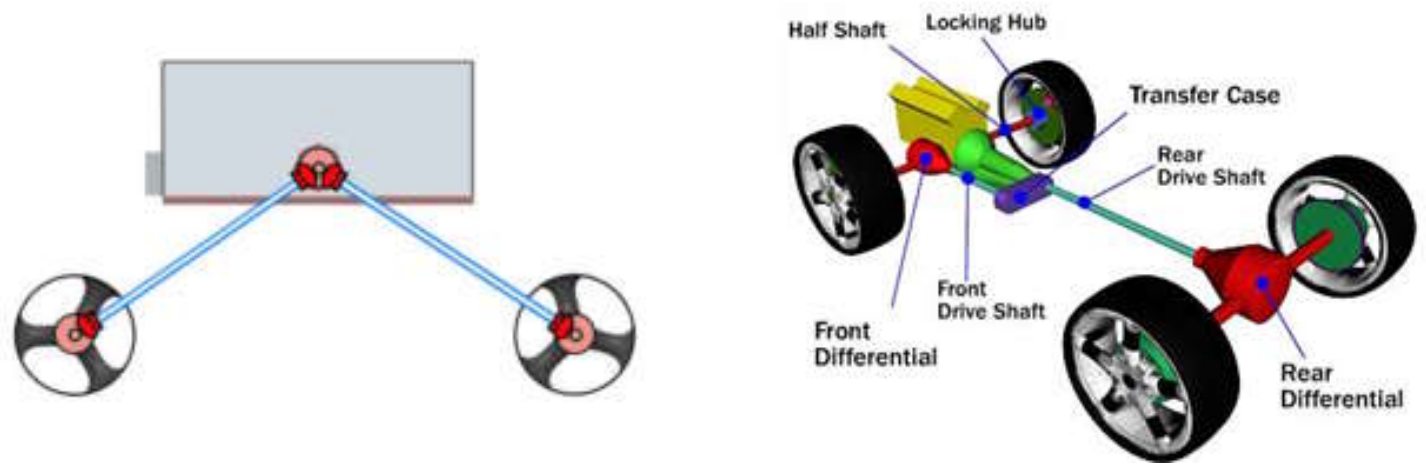

Figure 15. Dual-Output angle drive (left, courtesy University of Oklahoma) and standard four-wheel drive (right)

\section{Rover Dimensions}

Figures 16 and 17 shows the dimensions of the conceptual rover, which has a base width of 1.5 meters, a length of 2 meters and a height of 2.75 meters. The relatively small size enables the rover to fit into a designed aeroshell 3.35 meters high and 4.5 meters in diameter without folding, as shown in Fig. 17, which simplifies the design and avoids the need for complex folding mechanisms. The 4.5 meter diameter aeroshell is based on the Pioneer-Venus atmospheric-entry aeroshell; ${ }^{37}$ the bottom of the aeroshell is heat shield, and the top compartment will store the parachute system (not shown). Detailed analysis of aeroshell packing and entry, descent, and landing analysis was not conducted in this study.

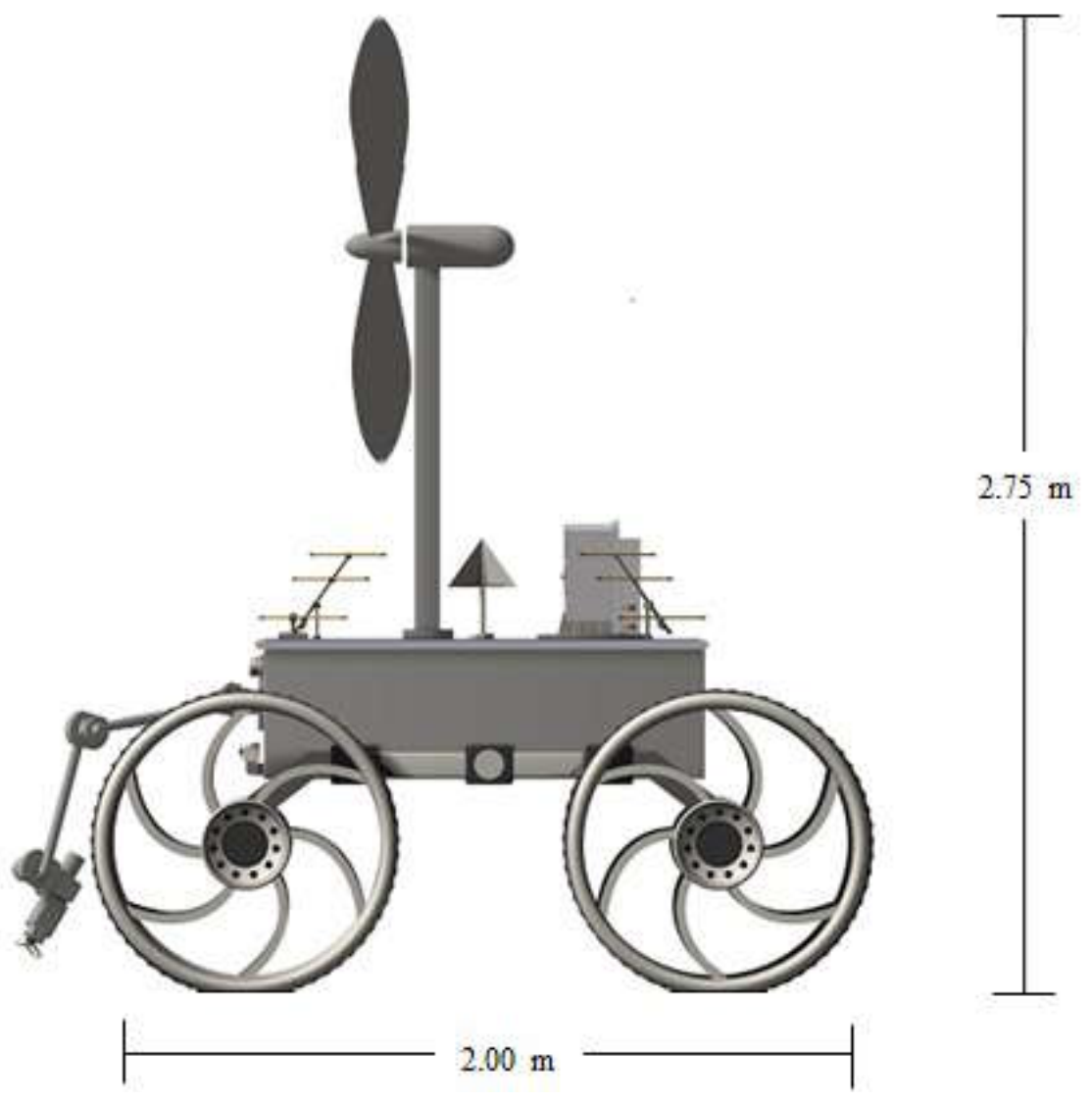

Figure 16. Dimensioned Rover (Side View) 


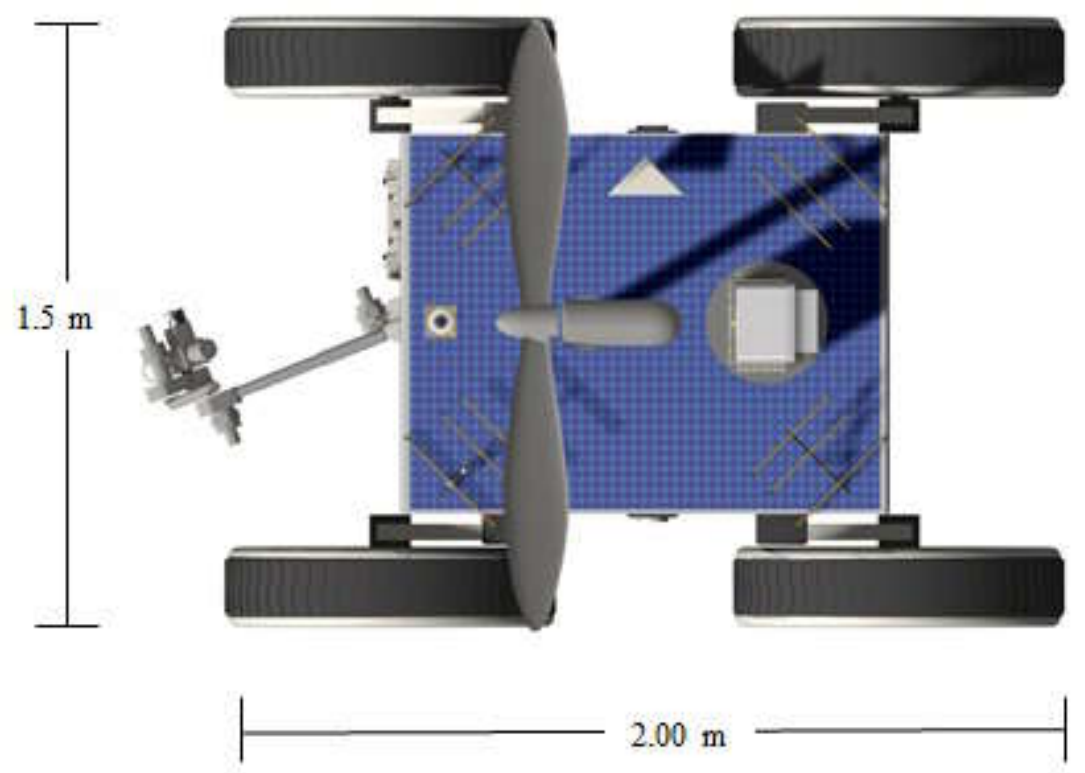

Figure 17. Dimensioned Rover (Top View)
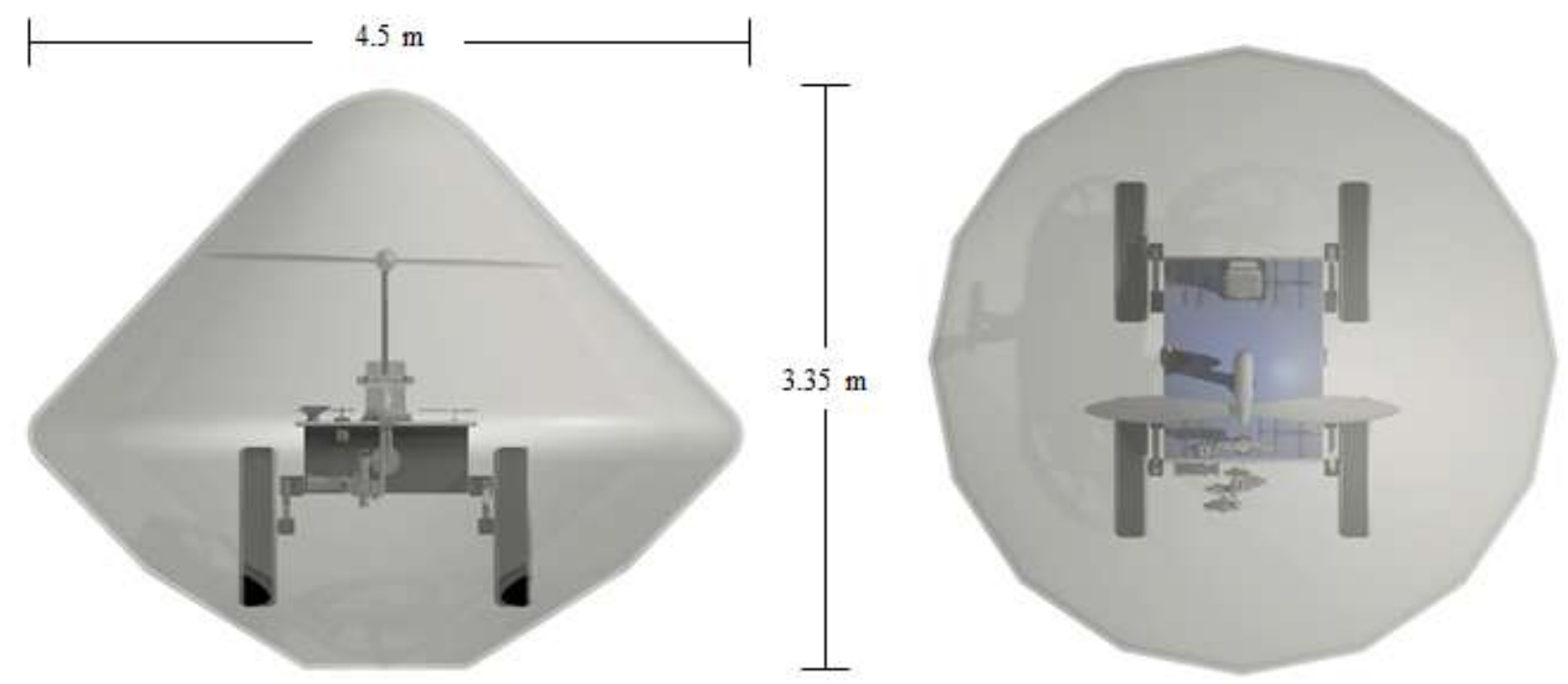

Figure 18. Rover fit in the Pioneer-Venus Large Probe aeroshell: Side View (Left) and Top View (Right)

\section{Communications Design}

The first step for the communications system was a trade study to decide between communication via an orbiting relay satellite to connect to Earth, or a direct to Earth transmission. Although use of a relay increases the mission cost by adding a second, orbiting, spacecraft, the antenna size and power required for a direct-to-Earth data link was prohibitive. To minimize the transmission power required, a design in which the rover communicates through an orbiting satellite was chosen to relay the data to Earth.

To determine the optimum orbiter altitude, the viewing angle from the center of Venus is calculated first. With an assumed viewing angle from the surface of $45^{\circ}$, the orbital angle from the center of Venus, $\gamma$, is:

$$
\gamma=\tan ^{-1}\left(\frac{h}{R+h}\right)
$$


where $h$ is the height from the surface, and the radius of Venus $\mathrm{R}$ is 6051.8 $\mathrm{km}$. The range of orbital altitude considered ranged from $200 \mathrm{~km}$ above the surface, barely above the Venusian atmosphere, to $10,000 \mathrm{~km}$ above the surface. As the altitude of the relay satellite increased, the viewing angle from the center of the Venus (and hence the fraction of the orbit that the relay is in view) increased accordingly, as shown in Fig. 19. The final calculation used the fraction of the orbit to calculate and find the highest fraction of power, including both the view angle and the $1 / \mathrm{r}^{2}$ power law, to find the altitude at which the highest bit rate to transfer data to and from Earth is achieved. The analysis showed that that the highest fraction of power received by the orbiter occurs with the lowest Venus orbit. Hence to get the highest amount of bits in a given period of time, the lowest Venus orbit is optimal.

The orbital speed as a function of communication orbiter's altitude is:

$$
V_{C}=\sqrt{\frac{\mu}{R+h}}
$$

where $\mu$ is Venus' standard gravitational parameter, $324,859 \mathrm{~km}^{3} / \mathrm{s}^{2}$. The orbiting velocity was then used to find the overhead time, in which the satellite was within the $45^{\circ}$ viewing angle. The time it took to take one full orbit around Venus was found using Kepler's law:

$$
t=\sqrt{\frac{4 \pi^{2} r^{3}}{\mu}}
$$

The amount of time the orbiter is in view of the lander (within $45^{\circ}$ of the zenith) is shown in Fig. 20.

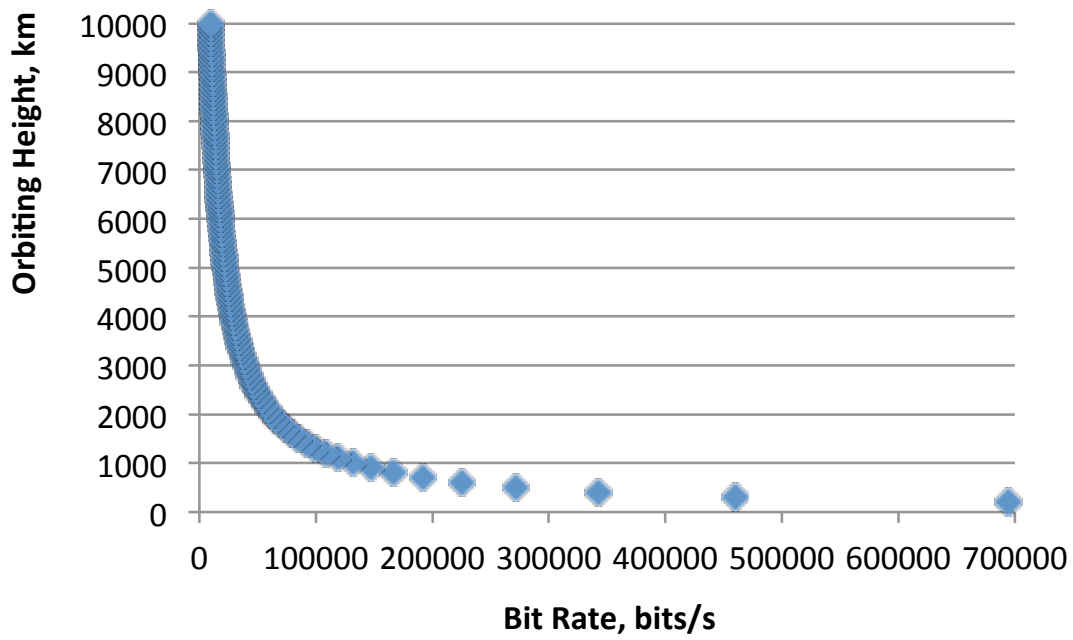

Figure 19. Bit Rate as a Function of Orbiting Satellite Height ${ }^{6}$

After finding the total bits/measurement for each instrument, the numbers of bits/measurement were totaled. This number was then used in conjunction with the overhead time to find the bit rate. For this part in the project, it was assumed that each instrument would only run once, and that the total number of bits would be able to be transferred to the orbiting satellite in one overhead pass. This way, the lowest bit rate per single overhead pass would be able to be found. In the most strained, basic scenario, each instrument would be able to run at least once and be able to transfer all of the data back to Earth in one overhead pass. These bit rates will inevitably change, depending on the amount of power designated to data transfer. It will also change due to the fact that the data coming from some instruments will require more frequent measurements than others. The NavCam, for example, will need to send a great deal of data back to Earth, to allow navigation to support driving. Other instruments, such as the CheMIN will need to send only one measurement back to Earth at a time. The frequency at which each instrument will take measurements has not yet been determined.

\footnotetext{
${ }^{6}$ Calculated using total number of bits/measurement.
} 


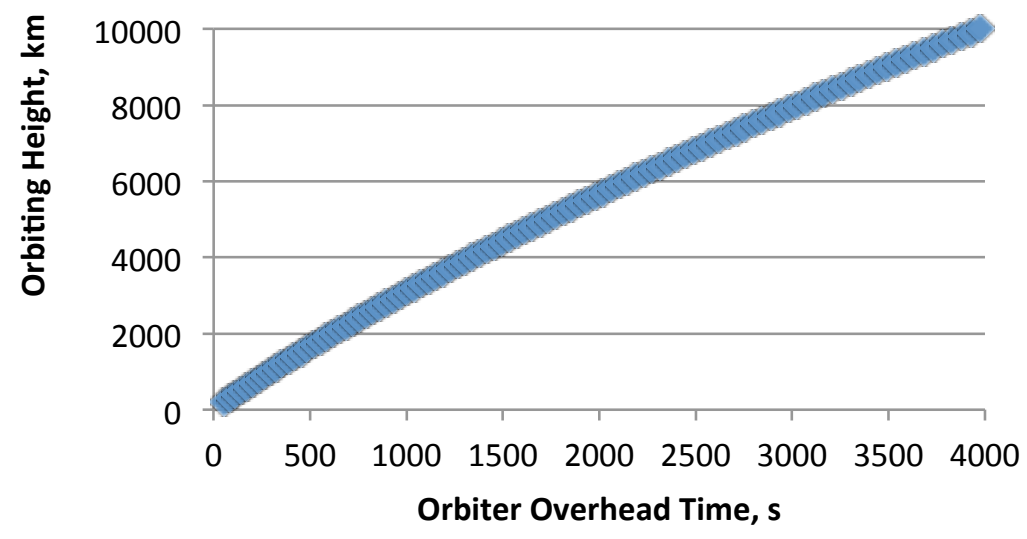

Figure 20. Satellite Overhead Time in Relation to Orbiting Height

\section{E. Radio Subsystem Design}

The radio subsystem design requires a trade-off between the efficiency of operation at high temperature, the radio opacity of the Venus atmosphere, and the complexity of tracking.

A solid-state radio system operating at a frequency of $500 \mathrm{MHz}$ was chosen. Despite Venus's thick and opaque atmosphere, a frequency of $500 \mathrm{MHz}$ is able to penetrate through the atmosphere, letting the rover connect to the orbiting satellite and send data back to Earth.

The transmission frequency was chosen to be one at which silicon-carbide power amplifiers have been demonstrated, in order to allow a fully solid-state transmitter operating at Venus ambient. NASA has successfully tested a differential oscillator operating at $500 \mathrm{MHz}$ at $475^{\circ} \mathrm{C},{ }^{42}$ a higher temperature than the surface of Venus, which demonstrates that the main power amplifier of the communications system can be designed to operate at the required temperatures.

The opacity of the Venus atmosphere to radio waves is a function of wavelength. Radar measurements show that the opacity in the microwave to VHF region can be modeled as: ${ }^{43}$

$$
\alpha=(3.8 / \lambda)^{2}
$$

where $\alpha$ is the absorption, and $\lambda$ the wavelength in $\mathrm{cm}$. At our target frequency of $500 \mathrm{MHz}(\lambda=60 \mathrm{~cm})$, the absorption of the radio signal by the atmosphere is too small to be significant. The chosen frequency lies between those used by the Russian Venera surface-to-relay communications, 122.8 and $138.6 \mathrm{MHz}$, and the Pioneer atmospheric probes transmission frequency, $2.3 \mathrm{GHz},{ }^{44}$ two previous missions which both successfully communicated from the surface of Venus to spacecraft overhead.

Omnidirectional antennas do not require pointing, but since they transmit in all directions, only a small fraction of the energy radiated is directed toward the receiver. An antenna with higher directivity (i.e., a high gain antenna) allows more of the transmitted energy to be received by the relay satellite and hence reduces the energy required per bit communicated, but puts constraints on the wavelengths or else requires larger antenna size. A high antenna gain also requires that the antenna be accurately pointed at the receiver. Antenna pointing adds to the complexity in the system, requiring either mechanical components (gimbal, motor) or a phased-array for electronic steering, as well as added computational complexity of understanding the rover orientation and tilt and calculating the satellite location relative to the rover. The three-element Yagi antenna chosen is a compromise between the simplicity of an omnidirectional antenna and the complexity of a dish. It provides a moderate gain of about $7.5 \mathrm{~dB}$ (compared to a dipole). As a result, it will require pointing. To mitigate the complexity of tracking, it was assumed that four Yagi antennas are mounted on the rover, and the transmitter output is switched to the appropriate antenna. The rover orientation may also be adjusted to optimally place the antenna pattern over the orbiter track.

\section{Conclusion}

The Curiosity mission to Mars has reminded the public of the value of rovers on extraterrestrial planets, and it is time to extend this capability to another planet, Venus. Venus is of scientific interest at least as great as the interest in Mars, and, the more can be found out about Venus by use of a rover mission, while the public is still excited and willing to support extraterrestrial planetary rovers. 
The benefit of having a rover on Venus is the fact that it can conduct science in more than one location, rather than being fixed at the landing spot. This, with the use of high temperature silicon-carbide electronics, may be exactly what is needed to find out the geological history and present geology and mineralogy of Venus. While it is difficult to design a rover to survive the surface conditions of Venus, that just means that this mission is that much more important. If there is no challenge, and nothing new to learn, then there would be no point to science at all. Venus has both of these components at large, making it one of the most scientifically interesting planets in our solar system.

\section{Acknowledgements}

The student researchers on this project enjoyed the support of the NASA Space Academy 2012 program. We would like to thank NASA Glenn artist Terence Condrich for his artist's conception of our rover, Dr. Kankam and Bernice Beznoska of NASA Glenn for their work hosting the NASA Space Academy, and our respective California and Maryland Space Grant Consortiums for their funding this summer.

\section{References}

${ }^{1}$ Loders, K., and Fegley Jr., B., The Planetary Scientist's Companion, Oxford, 1998, pp. 108-124.

${ }^{2}$ Neudeck P. G., Okojie R. S. , and Chen, L.-Y., "High-Temperature Electronics- A Role for Wide Bandgap Semiconductors," Proceedings of the IEEE, Vol. 90, No. 6, June 2002, pp. 1065-1076.

${ }^{3}$ Chen, L.-Y., Hunter, G. W., and Neudeck, P. G., "Silicon Carbide Die Attach Scheme for $500^{\circ} \mathrm{C}$ Operation," Proc. Materials Research Soc. Symposium 2000, Vol. 622, No. 1, Cambridge University Press, 2000, pp. 8101-8106..

${ }^{4}$ Hunter, G. W., Okojie, R. S., Neudeck, P. G., Beheim, G. M., Ponchak, G. E., Fralick, G., Wrbanek, J., Kraskowski, M., Spry, D., and Chen, L. Y., "High Temperature Electronics, Communications, and Supporting Technologies for Venus Missions," Fourth Annual International Planetary Probe Workshop, Pasadena, CA, June 2006.

${ }^{5}$ Kolawa, E., Extreme Environments Technologies for Future Space Science Missions, JPL D-32832, NASA, Sept. 19, 2007.

${ }^{6}$ Saunders, R. S., Spear, A. J., Allin, P. C., Austin, R. S., Berman, A. L., Chandlee, R. C., ... and Wall, S. D., "Magellan Mission Summary," Journal of Geophysical Research, 97 (E8), 1992, 13067-13. http://www2.jpl.nasa.gov/magellan/guide2.html.

${ }^{7}$ Landis, G. A., "Robotic Exploration of the Surface and Atmosphere of Venus," paper IAC-04-Q.2.A.08, Acta Astronautica, Vol. 59, No. 7, October 2006, pp. 517-580.

${ }^{8}$ Landis, G. A., Dyson, R., Oleson, S. J., Warner, J. D., Colozza, A. J., and Schmitz, P. C., "Venus Rover Design Study," paper AIAA-2011-7268, AIAA Space 2011 Conference \& Exposition, Long Beach CA, Sept. 26-29, 2011.

${ }^{9}$ Bennett, G. L., Lombardo, J. J., Hemler, R. J., and Peterson, J. R., "The General-purpose Heat Source Radioisotope Thermoelectric Generator - Power for the Galileo and Ulysses Missions," Proc. Intersociety Energy Conversion Engineering Conference (IECEC) '86, 1986, pp. 1999-2011.

${ }^{10}$ Wong, W. A., Wood, J. G., and Wilson, K., "Advanced Stirling Convertor (ASC)--From Technology Development to Future Flight Product," Space Technology and Applications International Forum (STAIF2008), Albuquerque, NM, February 10-14 2008; NASA/TM-2008-215282, 2008.

${ }^{11}$ Dyson, R. W., and Bruder, G. A., "Progress Towards the Development of a Long-Lived Venus Lander Duplex System," AIAA Paper 2010-6917, 8th AIAA International Energy Conversion Engineering Conference (IECEC), Nashville, TN, July 25-28, 2010; NASA/TM-2011-217018, 2011.

${ }^{12}$ Lafleur, J. D., "Nuclear Power Systems for Spacecraft," IEEE Transactions on Aerospace and Electronic Systems, Vol. 2, 1970, pp. 147-164.

${ }^{13}$ Keldysh, M. V., "Venus Exploration with the Venera 9 and Venera 10 Spacecraft," Icarus, 30 (4), 1977, pp. 605-625.

${ }^{14}$ Ksanfomalti, L., Goroshkova, N., and Khondyrev, V., "Wind Velocity at the Venus Surface According to Acoustic Measurements," Kosmicheskie Issledovaniia, 21, Mar-April 1983, pp. 218-224. In English: http://md1.csa.com/partners/viewrecord.php?requester=gs\&collection=TRD\&recid=A8331961 AH 
${ }^{15}$ Landis, G. A., "A Landsailing Rover for Venus Mobility," Journal of the British Interplanetary Society, to be published (2013).

${ }^{16}$ Kimball, J., Physics of Sailing, Taylor and Francis Group, Boca Raton, FL, 2010. 978-1-4200-7376-8.

${ }^{17}$ Marchaj, C. A., Aero-Hydrodynamics of Sailing, 3rd edition, Tiller Publishing, Easton, MD, 2000. ISBN-13: 978-1888671186.

${ }^{18}$ Landis, G. A. and Vo, T., "Photovoltaic Performance in the Venus Environment," 34th IEEE Photovoltaic Specialists Conference, Philadelphia PA, 7-12 June 2009; in updated form as Landis, G. A., and Haag, E., "Analysis of Solar Cell Efficiency for Venus Atmosphere and Surface Missions" AIAA 11th International Energy Conversion Engineering Conference, San Jose CA, July 2013.

19 Ji, J., Narine, R., Kumar, N., Singh, S., and Gorevan, S., "High Temperature Mechanisms for Venus Exploration," 37th COSPAR Scientific Assembly, Vol. 37, 2008, p. 1370.

${ }^{20}$ Harrison, R., and Landis, G. A., "Batteries for Venus Surface Operation," Paper AIAA-2008-5796, Journal of Propulsion and Power, Vol. 26, Number 4, July/Aug 2010, pp., 649-654.

${ }^{21}$ Park, J., The Wind Power Book, Chesire, Palo Alto, CA, 1981.

${ }^{22}$ Ragheb, M., and Ragheb, A. M., "Wind Turbines Theory- The Betz Equation and Optimal Rotor Tip Speed Ratio," in R. Carriveau, Fundamental and Advanced Topics in Wind Power, 2011, pp. 19-37.

${ }^{23}$ Livingston, T., "Space Frame Towers," California Wind Energy Collaborative, Wind Tower Composites, 2005.

${ }^{24}$ Griffin, D. A., Blade System Design Studies, Volume II: Preliminary blade designs and recommended test matrix; SAND2004-0073, United States Department of Energy, 2004.

25 Honeybee Robotics, "Data Sheet: High Temperature Motor / Extreme Environment Actuator," http://www.honeybeerobotics.com/images/stories/pdf/HTM_Data_Sheet.pdf

${ }^{26}$ Gómez-Elvira, J., Castañer, L., Lepinette, A., Moreno, J., Polko, J., Sebastián, E., Torres, J., Zorzano, M. T., and the REMS Team, "REMS, an Instrument for Mars Science Laboratory Rover," Lunar and Planetary Institute Science Conference Abstracts, Vol. 40, March 2009, p. 1540.

${ }^{27}$ Rieder, R., et al., "The New Athena Alpha Particle X-ray Spectrometer for the Mars Exploration Rovers," Journal of Geophysical Research, Vol. 108, November 11, 2003, p. 13.

${ }^{28}$ Shanmugam, M., Acharya, Y. B., Goyal, S. K., and Murty, S. V. S., "Alpha Particle X-Ray Spectrometer (APXS) On-Board Chandrayaan-2 Rover," Lunar and Planetary Institute Science Conference Abstracts, Vol. 42, March 2011, p. 1232.

${ }^{29}$ Gellert, R., Campbell, J. L., King, P. L., Leshin, L. A., Lugmair, G. W., Spray, J. G., ... and Yen, A. S., "The Alpha-Particle-X-Ray Spectrometer (APXS) for the Mars Science Laboratory (MSL) Rover Mission," 40th Lunar and Planetary Science Conference, Houston, TX, March 2009. Lunar and Planetary Institute, Vol. 3600 .

${ }^{30}$ Christensen, P. R., et al., "The Miniature Thermal Emission Spectrometer for the Mars Exploration Rovers," Journal of Geophysical Research, Vol. 108, December 24, 2003, p. 23.

${ }^{31}$ Blake, D., et. al., "Characterization and Calibration of the CheMin Mineralogical Instrument on Mars Science Laboratory," Space Science Reviews, Vol. 170, No. 1-4, 2012 (DOI: 10.1007/s11214-012-9905-1), pp. 341399.

${ }^{32}$ Gorevan, S. P., Myrick, T., Davis, K., Chau, J. J., Bartlett, P., Mukherjee, S., and Richter, L., "Rock Abrasion Tool: Mars Exploration Rover Mission," Journal of Geophysical Research, Vol. 108 (E12), 2003, 8068.

${ }^{33} \mathrm{Ji}$, J, "High Temperature Mechanisms," Short Course on Extreme Environment Technology, 6th International Planetary Probe Workshop, Atlanta GA, June 21-22 2008.

${ }^{34}$ Herkenhoff, K. E., et al., "Athena Microscopic Imager investigation," Journal of Geophysical Research, Vol. $108,2003$.

${ }^{35}$ Bell III, J. F., et al., "Mars Exploration Rover Athena Panoramic Camera (Pancam) investigation," Journal of Geophysical Research, 108 (E12), 2003, 8063.

${ }^{36}$ Maki, J. N., et al., "Mars Exploration Rover Engineering Cameras," Journal of Geophysical Research, Vol. 108, American Geophysical Union, 2003.

${ }^{37}$ Fimmel, R. O., Colin, L. and Burgess, E., Pioneer Venus, NASA report SP-461, 1983.

${ }^{38}$ Garvin, J., Head, J., Zuber, M., and Helfenstein, P., "Venus: the Nature of the Surface from Venera Panoramas," J. Geophys. Res., 89, B5, May 10 1984, pp. 3381-3399.

${ }^{39}$ Bond, P., Exploring the Solar System, John Wiley \& Sons, Hoboken, NJ, 2012.

${ }^{40}$ Gottlieb, I., Electric Motors and Control Techniques, McGraw-Hill, 1994. 
${ }^{41}$ Roman, M. J., Design and Analysis of a Four-Wheeled Planetary Rover. University of Oklahoma, Norman, OK, 2005.

${ }^{42}$ Hunter, G., et al., "Development of High Temperature Wireless Sensor Technology Based on Silicon Carbide Electronics," ECS Transactions, 33(8), The Electrochemical Society, 2010, pp. 269-281.

${ }^{43}$ Muhleman, D. O., "Microwave Opacity of the Venus Atmosphere," Astronomical Journal, Vol. 74, No. 1, 5768, February 1969 (DOI 10.1086/110776).

${ }^{44}$ Smith, J. R., and Ramos, R., "Data Acquisition for Measuring the Wind on Venus from Pioneer Venus," Telecommunications and Data Acquisition Progress Report 42-57, IEEE Transactions on Geoscience and Remote Sensing, vol. GE-18, No. 1, January 1980, pp. 126-130. 